\title{
Primer balance del nuevo recurso de casación contencioso-administrativo
}

\author{
José Antonio Razquin Lizarraga
}

DOI: https://doi.org/10.47623/ivap-rvap.110.2018.1.08

\begin{abstract}
Sumario: I. Primer año del nuevo recurso de casación.-II. Resoluciones recurribles en casación. 1. Sentencias de los Juzgados. 2. Autos de las Salas. 3. Resoluciones del Tribunal de Cuentas.-III. Alcance del recurso. 1. Cuestiones jurídicas con exclusión de las fácticas. 2. Infracciones del derecho estatal o comunitario europeo.-IV. Legitimación.-V. El interés casacional objetivo; piedra angular de la nueva casación. 1. Circunstancias ejemplificativas. 2. Presunciones. 3. Presupuesto básico: formación de jurisprudencia.-VI. Los vicios procedimentales en el nuevo recurso de casación 1. Incongruencia omisiva: exigencia de un nuevo trámite para acceder a la casación. 2. Escasa viabilidad y carácter accesorio de las infracciones de carácter procesal. 3. Impacto sobre el incidente de nulidad de actuaciones.-VII. Preparación del recurso de casación: 1. Esencialidad y rigor del escrito de preparación: requisitos, insubsanabilidad y forma. 2. Cumplimiento de los requisitos reglados: recurribilidad de las resoluciones. 3. Identificación de las normas o jurisprudencia, juicio de relevancia y justificación de su carácter estatal o comunitario. 4. Denuncia previa de las infracciones de carácter procesal. 5. Fundamentación del interés casacional objetivo y de la conveniencia de pronunciamiento del TS. - VIII. Papel de los órganos de instancia.IX. Admisión del recurso. 1. Objeto y estructura de las decisiones. 2. Procedimiento y forma de las resoluciones. 3. Recursos admitidos. 4. Costas. -X. El carácter jurisprudencial de la sentencia final. $-X I$. Los problemas del recurso de casación autonómico.-XII. Conclusión
\end{abstract}

\section{Primer año del nuevo recurso de casación}

El nuevo recurso de casación en el orden contencioso-administrativo, establecido por la Ley Orgánica 7/2015, de 21 de julio, que modificó la Ley de la Jurisdicción Contencioso-Administrativa (LJCA)(1), ha cumplido un

(1) Sobre el nuevo recurso de casación existe una amplia bibliografía. Pueden consultarse, entre otros, RAZQUIN LIZARRAGA, José Antonio, "El recurso de casación en la jurisdicción contencioso-administrativa tras la Ley Orgánica 7/2005», en RVAP núm. 104, 2016, págs. 135-178; 
año desde su efectividad a partir del 22 de julio de 2016, lo que permite analizar su implantación por los tribunales de casación.

El análisis va a centrarse en el recurso de casación estatal ante el Tribunal Supremo (TS), por ser el objeto principal de la nueva regulación, sin perjuicio de considerar también, de forma breve, el recurso de casación autonómico donde su insuficiente regulación específica ha provocado criterios contradictorios entre las Salas territoriales.

La nueva regulación dejaba en manos de la Sala Tercera delTS un amplio espacio de acción para clarificar y completar la configuración del recurso de casación, definiendo un régimen acabado y su efectiva virtualidad(2) y dando respuesta a las dudas y cuestiones derivadas de las relevantes novedades de la reforma (3).

En este primer año, el TS ha dictado un importante número de resoluciones sobre la admisión y dos sentencias. Las resoluciones publicadas (autos de admisión, de inadmisión y resolutorios de recursos de queja; y sentencias) marcan unas iniciales pautas interpretativas, en particular respecto de la admisión del recurso que es la clave de la nueva casación, que permiten esbozar la conformación de ese nuevo modelo (4).

SANTAMARÍA PASTOR, Juan Alfonso, "Una primera aproximación al nuevo sistema casacional», en RAP núm. 198, 2015, págs. 11-42; FERNÁNDEZ FARRERES, Germán José, “Sobre la eficiencia de la jurisdicción contencioso-administrativa y el nuevo recurso de casación "para la formación de la jurisprudencia"”, en REDA núm. 174, 2015, págs. 94-95; LOZANO CUTANDA, Blanca, "La reforma del recurso de casación contencioso-administrativo por la Ley Orgánica 7/2015: análisis de sus novedades", en Diario La Ley núm. 8599, 7 de septiembre de 2015 y en Diario La Ley núm. 8609, de 21 de septiembre de 2015; GONZÁLEZ-VARAS IBÁNEZ, Santiago, "Comentarios al nuevo recurso de casación (1): artículos 86 y 87 de la LJCA tras la Ley Orgánica 7/2015, de 21 de julio", en Revista Aranzadi Doctrinal núm. 7, 2016, págs. 75-99; QUINTANA CARRETERO, Juan Pedro, CASTILLO BADAL, Ramón y ESCRIBANO TESTAUT, Pedro, en Guía práctica del Recurso de Casación Contencioso-Administrativo, Ed. Dykinson, Madrid, 2016; CANCIO FERNÁNDEZ, Raúl, El nuevo recurso de casación en el orden contencioso-administrativo, Ed. Thomson Reuters Aranzadi, Cizur Menor (Navarra), 2015; HINOJOSA MARTÍNEZ, Eduardo, El nuevo recurso de casación contencioso-administrativo, Ed. Bosch, Barcelona, 2016; y CAZORLA PRIETO, Luis María y CANCIO FERNÁNDEZ, Raúl César (coords.), Estudios sobre el Nuevo Recurso de Casación Contencioso-Administrativo, Ed. Aranzadi, Cizur Menor (Navarra), 2017.

(2) RAZQUIN LIZARRAGA, "El recurso...», op. cit., pág. 177; y VELASCO CABALLERO, Francisco, «Poderes del Tribunal Supremo en la casación contencioso-administrativa», en Revista española de Derecho Administrativo, núm. 182, 2017, §§ 7 y 38.

(3) MUÑOZ ARANGUREN, Arturo, "La curiosidad del jurista persa y la reforma del recurso de casación contencioso-administrativo", en Diario La Ley, N. ${ }^{\circ} 8638$, de 28 de octubre de 2015; RAZQUIN LIZARRAGA, José Antonio, "Problemas del nuevo recurso de casación contencioso-administrativo", en Revista Aranzadi Doctrinal, núm. 11, 2016, págs. 51-70, y FERNÁNDEZ GARCíA, José Francisco, "Lo nuevo y lo viejo del recurso de casación contencioso-administrativo: admisibilidad y motivos de impugnación", en RAP núm. 202, 2017, págs. 337-379.

(4) HUELÍN MARTÍNEZ DE VELASCO, Joaquín, "La nueva casación contencioso-administrativa (primeros pasos)", en Revista General de Derecho Constitucional, núm. 24, 2017; y ESCRIBANO TESTAUT, Pedro, "Doctrina jurisprudencial sobre la nueva regulación del Recurso de Casación (L.O. 7/2015)», CGPJ (Web del Tribunal Supremo), 2017 
Así pues, partiendo de la regulación de la nueva casación contenciosoadministrativa, se estudia la primera jurisprudencia sobre el nuevo recurso de casación, ofreciendo su interpretación de la nueva regulación y un primer balance de su aplicación por elTS.

\section{Resoluciones recurribles en casación}

El nuevo recurso de casación ante elTS tiene un ámbito cuasi universal y abarca cuatro supuestos: sentencias en instancia o en apelación de las Salas de lo Contencioso-Administrativo de la Audiencia Nacional y de los Tribunales Superiores de Justicia, sentencias dictadas en única instancia por los Juzgados, sentencias delTribunal de Cuentas sobre responsabilidad contable y autos de las citadas Salas (arts. 86 y 87 LJCA). El primero de ellos, pese a la novedad incorporada, no planteaba problemas por lo que el recurso se extiende con normalidad también a las sentencias de apelación. En cambio, ha sido preciso abordar las cuestiones suscitadas por los restantes mediante una interpretación de dichos preceptos legales.

\section{Sentencias de los Juzgados}

La recurribilidad de las sentencias dictadas en única instancia por los Juzgados de lo Contencioso-administrativo - aunque contaba con el precedente del recurso de casación en interés de ley- se considera una de las novedades del nuevo sistema (art. 86 LJCA) que comprende las sentencias definitivas de los Juzgados de lo Contencioso-administrativo y también las de los Juzgados Centrales de lo Contencioso-Administrativo, esto es, la sentencias dictadas en única instancia por los órganos unipersonales (5).

Ahora bien, su impugnabilidad en casación es limitada por exigirse la concurrencia acumulativa de dos requisitos: que la sentencia contenga doctrina que se reputa gravemente dañosa para los intereses generales y que se trate de una resolución susceptible de extensión de efectos (art. 86.1, párrafo segundo, LJCA) (6). La jurisprudencia se ha centrado en la interpretación del segundo de tales presupuestos de recurribilidad (extensión de efectos), que tiene carácter reglado frente a la estimación discrecional del primero (gravemente dañosa para el interés general) por el

(5) AATS de 27 de febrero de 2017 (Rec. Queja 36/2017); de 5 de abril de 2017 (Rec. Queja 42/2017) de 30 de mayo de 2017 (Rec. Queja 265/2017) y de 10 de julio de 2017 (Rec. Queja 112/2017).

(6) ATS de 15 de febrero de 2017 (Rec. Queja 120/2016), de 5 de abril de 2017 Rec. Queja 42/2017), ATS de 26 de abril de 2017 (Rec. Queja 177/2017), de 22 de mayo de 2017 (Rec. Queja 289/2017), de 29 de mayo de 2017 (Rec. Queja 228/2017), de 30 de mayo de 2017 (Rec. Queja 265/2017) y de 10 de julio de 2017 (Rec. Queja 112/2017). 
TS, lo que ocasiona - como más adelante se indicará- una dispar posición de los órganos de instancia respecto de cada uno de ellos.

El requisito de que la sentencia sea susceptible de extensión de efectos ha de entenderse de la manera contemplada en los arts. 110 y 111 LJCA; en concreto, el art. 110 configura la posibilidad de extensión de efectos de una sentencia firme con dos condiciones: en materia tributaria, de personal al servicio de la Administración pública o de unidad de mercado y que reconozca una situación individualizada a favor de una o varias personas (7).

Esa primera condición exige que la sentencia verse sobre una de las materias contenidas en el art. 110 (o concurra el presupuesto previsto en el art. 111 LJCA), pues en otro caso no puede accederse a la casación(8). Se cumple esta condición si se trata de una cuestión referida a la unidad de mercado (el debate gira en torno a la libertad de establecimiento y prestación de servicios)(9) o relativa a tributos(10); y, en cambio, no concurre cuando la cuestión se refiere a la reclamación de indemnización(11), a deudas por cuotas de la empresa o liquidación de diferencias de cotización a la Seguridad Social (12) o a cuotas de urbanización giradas por Junta de Compensación dado su carácter no tributario a estos efectos(13).

La segunda condición del art. 110 LJCA requiere el reconocimiento de una situación jurídica individualizada a la parte recurrente - esto es, alguna titularidad básica (derecho subjetivo) o, al menos, subordinada adoptando, en su caso, cuantas medidas sean necesarias para el pleno restablecimiento de la misma (arts. 31.2 y 71.1.b) LJCA) - que sea susceptible de extensión de efectos, por lo que no concurre cuando la sentencia que se impugna es de signo desestimatorio(14). Así pues, es condición ineludible que la sentencia sea estimatoria, pues en otro caso no es susceptible de extensión de efectos, lo que restringe la legitimación para recurrir a las Administraciones públicas demandadas (15).

(7) AATS de 5 de abril de 2017 (Rec. Queja 38/2017) y de 30 de mayo de 2017 (Rec. Queja 265/2017).

(8) ATS de 15 de febrero de 2017 (Rec. Queja 129/2016).

(9) ATS de 13 de marzo de 2017 (Rec. Casación 313/2016).

(10) AATS de 1 de marzo de 2017 (Rec. Casación 128/2016l) y de 21 de junio de 2017 (Rec. Casación 1636/2017).

(11) ATS de 10 de julio de 2017 (Rec. Queja 112/2017).

(12) AATS de 8 de febrero de 2017 (Rec. Queja 135/2016) y de 5 de junio de 2017 (Rec. Queja 209/2017).

(13) ATS de 22 de febrero de 2017 (Rec. Queja 164/2016).

(14) AATS de 8 de marzo de 2017 (Rec. Queja 65/2017), de 22 de marzo de 2017 (Rec. Queja 60/2017), de 22 de marzo de 2017 (Rec. Queja 143/2016), de 26 de abril de 2017 (Rec. Queja 177/2017), de 8 de mayo de 2017 (Rec. Queja 84/2017) y de 26 de julio de 2017 (Rec. Queja 314/2017).

(15) Como adujo el recurrente, ello repercute en la legitimación para impugnar estas resoluciones que se limita a las Administraciones públicas y sus codemandados: ATS de 26 de abril de 2017 (Rec. 
Salvo esa especialidad relativa a la recurribilidad, que habrá de acreditarse en el escrito de preparación [art. 89.2.a) LJCA], el recurso de casación contra sentencias definitivas de los Juzgados se sujeta al régimen único y general, entendiendo que las referencias a las Salas de instancia incluyen también a los Juzgados. Por ello, la existencia de interés casacional objetivo pueda apreciarse con base en la concurrencia no sólo del supuesto del art. 88.2.b), claramente emparentado con una de las condiciones de impugnabilidad, sino también de otros supuestos fijados en los apartados 2 y 3 del art. 88 LJCA (16).

\section{Autos de las Salas}

El régimen jurídico y el plazo para interponer el recurso de casación contra los autos de las Salas de lo Contencioso-administrativo de la Audiencia Nacional y de los Tribunales Superiores de Justicia dependen de la fecha del auto que resuelve el recurso de reposición(17); de modo que puede impugnarse un auto resolutorio del recurso de reposición contra una providencia(18). La limitación a los autos de las Salas deja fuera los autos de los Juzgados; si bien éstos últimos pueden resultar recurridos de forma mediata cuando sobre ellos se haya pronunciado en apelación una Sala, cuya sentencia es siempre susceptible de casación(19).

La recurribilidad en casación de los autos de las Salas no es general, sino que está restringida a las cinco clases determinadas en el art. 87.1 LJCA(20), lo que debe justificarse en el escrito de preparación [art. 89.2.a) LJCA].

Queja 177/2017). En este sentido, HUELÍN MARTíNEZ DE VELASCO, op. cit.; y HUERGO LORA, Alejandro, «El recurso de casación en interés de la ley tras la reforma de 2015: ¿Desaparición, transformación o inconstitucionalidad?», en LAGUNA DE PAZ, José Carlos, SANZ RUBIALES, Iñigo y MOZOSYTOUYA, Isabel María de los (Coords.), Derecho Administrativo e Integración Europea. Estudios en homenaje al Profesor José Luis Martínez López-Muñiz, Ed. Reus, Madrid, 2017, págs. 1530-1537, quien critica que sea una vía de recurso reservada a la Administración demandada por entrañar un trato desigual con el demandante contrario a la igualdad de armas integrante del derecho fundamental a la tutela judicial efectiva.

(16) AATS de 1 de marzo de 2017 (Rec. Casación 128/2016) y de 13 de marzo de 2017 (Rec. Casación 313/2016).

(17) AATS de 1 de febrero de 2017 (Rec. Queja 2989/2016), de 2 de febrero de 2017 (Rec. Queja 110/2016) y 15 de marzo de 2017 (Rec. Queja 125/2016).

(18) ATS 15 de febrero de 2017 (Rec. Queja 100/2016).

(19) Así se admiten los recursos de casación contra sentencias de apelación frente a autos de Juzgados sobre satisfacción extraprocesal (ATS de 13 de marzo de 2017, Rec. Casación 54/2017), respecto de entrada en domicilio (ATS de 29 de marzo de 2017, Rec. Casación 1062/2017) y sobre ejecución de sentencia (ATS de 20 de julio de 2017, Rec. Casación 2225/2017).

(20) MUÑOZ ARANGUREN, «EI recurso de casación contra autos recaídos en ejecución de sentencia tras la entrada en vigor de la reforma de la Ley de la Jurisdicción Contencioso-administrativa”, en Revista Aranzadi Doctrinal, núm. 6, 2017, págs. 29-44. 
Al margen de esa limitación, es aplicable el régimen general de la casación. Por tanto, el recurrente debe cumplir los requisitos exigidos para el escrito de preparación y, en particular, justificar la relevancia de las infracciones denunciadas y su carácter determinante del sentido del faIlo [art. 89.2.b) LJCA] y argumentar sobre el interés casacional objetivo para la formación de jurisprudencia [89.2.f) LJCA], cuya existencia se alegará y ponderará de acuerdo con el art. 88.2 y 3 LJCA, por lo que, en caso de estimación negativa, se inadmite el recurso(21).

\section{Resoluciones del Tribunal de Cuentas}

La recurribilidad en casación de las resoluciones del Tribunal de Cuentas en materia de responsabilidad contable planteaba importantes incógnitas en razón de la remisión a los casos establecidos en la Ley de Funcionamiento del Tribunal de Cuentas - que no fue modificada(art. 86.4 LJCA). Han sido resueltas por el TS mediante los dos criterios siguientes: 1) Son recurribles en casación las sentencias definitivas pronunciadas por las Salas del Tribunal de Cuentas en apelación o en única instancia en materia de responsabilidad contable con independencia de la cuantía del procedimiento en el que se hubieran dictado, así como los autos referidos en el art. 81.2, apartados $2 .^{\circ}$ y $3 .^{\circ}$ de la Ley de Funcionamiento del Tribunal de Cuentas; y 2) Al recurso de casación contra tales sentencias son aplicables los requisitos fijados para el escrito de preparación en el art. 89.2 LJCA y puede fundarse en cualquier infracción del ordenamiento jurídico o de la jurisprudencia, sin que ajustarse a los motivos previstos en el art. 82.1 de la Ley de Funcionamiento del Tribunal de Cuentas (22).

\section{Alcance del recurso}

\section{Cuestiones jurídicas con exclusión de las fácticas}

El recurso de casación se limita a las cuestiones de derecho, con exclusión de las cuestiones de hecho (art. 87.bis.1 LJCA), por lo que no cabe plantear cuestiones fácticas y especialmente la revisión de la valoración de la prueba realizada por el órgano de instancia.

(21) AATS de 24 de abril de 2017 (Rec. Casación 611/2017) y de de 29 de mayo de 2017 (Rec. Queja 108/2017).

(22) ATS de 31 de mayo de 2017 (RCA 60/2017), cuya doctrina se reitera en AATS de 15 de junio de 2017 (Rec. Queja 223/2017) y de 21 de junio de 2017 (Rec. Queja 220/2017). 
La admisión excepcional y restrictiva de la discusión sobre la valoración de la prueba en el antiguo recurso de casación pasa a ser mucho más excepcional y restrictiva en la actual y novedosa regulación del recurso caracterizada por su finalidad hermenéutica del Derecho público y la posición basilar de la noción de interés casacional objetivo para la formación de la jurisprudencia, resultando ajenas a esa finalidad las impugnaciones circunscritas a la discusión sobre la apreciación por el órgano judicial de instancia de los hechos subyacentes en el pleito; por lo que han de quedar excluidas del actual recurso de casación las cuestiones en las que la parte manifiesta su discrepancia con el resultado valorativo de la prueba realizado por el tribunal a quo, que revelan una discrepancia con el resultado de dicha valoración sin plantear una infracción de la norma jurídica que establece los criterios de valoración que debe utilizar un tribunal al enjuiciar este tipo de pruebas (23).

Por tanto, este art. 87 bis. 1 LJCA justifica la inadmisión de la casación por más que la parte recurrente pretenda disfrazar la cuestión de ropajes jurídicos cuando en realidad se trata de una cuestión de prueba en la que el Tribunal de casación no puede adentrarse (24), o incluso que no se tenga por preparado el recurso cuando el recurrente se limita a plantear la mera discrepancia con la apreciación de los hechos efectuada por el órgano judicial de instancia tratándose de un recurso que se mueve únicamente por el terreno vedado de las apreciaciones fácticas (25). Así pues, la imputación de una errónea valoración de la prueba efectuada no tiene encaje en ninguno de los apartados del art. 88 LJCA ni en ningún otro y el propio art. 87.bis. 1 LJCA excluye de este recurso extraordinario las cuestiones de hecho(26). Ello es especialmente relevante en materia de responsabilidad patrimonial por su carácter primordialmente fáctico (27).

Sin embargo, decidir si se está en presencia de una cuestión fáctica o jurídica no es siempre lineal; y así si se discute sobre la valoración de un documento a efectos de interrumpir la prescripción de la acción de res-

(23) ATS de 19 de junio de 2017 (Rec. Queja 273/2017).

(24) ATS de 8 de marzo de 2017 (Rec. Casación 242/2016).

(25) ATS de 8 de marzo de 2017 (Rec. Queja 8/2017) y de 19 de junio de 2017 (Rec. Queja 317/2017).

(26) ATS de 26 de junio de 2017 (Rec. Casación 1829/2017).

(27) Según el ATS de 29 de mayo de 2017 (Rec. Queja 230/2017), la pretensión de una valoración alternativa de la actividad probatoria realizada por el tribunal es cuestión ajena al recurso de casación y que forma parte del sustrato fáctico y probatorio del recurso, sin que sea aceptable la afirmación de que la discrepancia jurídica surge por el hecho de que en diferentes supuestos de responsabilidad patrimonial sanitaria diversas sentencias lleguen a resultados diferentes, pues esa contradicción lo es de la doctrina jurídica y no del sentido del fallo. 
ponsabilidad patrimonial ejercitada, este punto valorativo, obliga, en principio, a excluir la naturaleza fáctica del documento controvertido (28).

Finalmente, continúa siendo plenamente aplicable la jurisprudencia anterior que proscribe la introducción de cuestiones nuevas en casación. Pese a no contemplarse explícitamente esta causa de inadmisión en la nueva regulación, un recurso de casación que se sitúe en este inadecuado escenario podrá ser inadmitido, bien por no justificarse debidamente que las normas cuya infracción se denuncia fueron alegadas en el proceso o tomadas en consideración por el Tribunal -o que este debió tomarlas en consideración aún sin ser alegadas- [arts. 89.2.b) y 90.4.b) LJCA], bien por no justificarse la relevancia sobre el fallo de tales infracciones [arts. 89.2.d) y 90.4.b) LJCA] (29). Así pues, no puede entrarse a considerar aquellas cuestiones que no fueron objeto de debate $\mathrm{ni}$, en consecuencia, de pronunciamiento por parte de la sentencia recurrida en casación (30).

\section{Infracciones del derecho estatal o comunitario europeo}

El recurso de casación ante elTS se ciñe a las infracciones del Derecho estatal y del Derecho comunitario europeo (arts. 86.3, 87.1 y 93.1 LJCA). Esa demarcación, que debe justificarse en el escrito de preparación respecto de la impugnación de resoluciones de las Salas territoriales [art. 89.2.d) LJCA], plantea interrogantes ante el posible entrecruzamiento y convergencia de normas del derecho autonómico con el derecho estatal y comunitario europeo.

La recurribilidad de las sentencias en el recurso de casación estatal obedece no tanto a la naturaleza estatal o autonómica de las normas aplicadas en el proceso sino, en relación con la fundamentación jurídica de la sentencia, al carácter estatal de las normas en que el recurrente pretende basar su recurso, que se han de anticipar en el escrito de preparación (31).

Por tanto, son recurribles en casación ante el TS las sentencias de las Salas de los Tribunales Superiores de Justicia sobre disposiciones generales autonómicas si las normas y cuestiones planteadas en el escrito de preparación versan sobre derecho estatal (infracción del sistema de com-

(28) ATS de 26 de mayo de 2017 (Rec. Queja 151/2017).

(29) ATS de 3 de febrero de 2017 /Rec. Casación núm. 203/2016).

(30) AATS de 1 de marzo de 2017 (Rec. Casación 148/2016) y de 21 de marzo de 2017 (Rec. Casación 308/2016).

(31) ATS de 26 de junio de 2017 (Rec. Queja 295/2017). 
petencias o del ordenamiento estatal aplicable)(32). Asimismo, es admisible el recurso respecto de la interpretación de normas tributarias de derecho autonómico si son idénticas a las estatales y se trata de tributos armonizados en la Unión Europea(33); o si el contenido de un precepto de derecho autonómico es idéntico al de un precepto de derecho estatal, puede invocarse como motivo de casación la infracción de la jurisprudencia recaída en interpretación de este último, habiéndose invocado además como precepto infringido el art. 31 CE (34). En cambio, cuando la única normativa alegada como infringida es la autonómica o se está ante un caso de interpretación o aplicación del Derecho autonómico, no puede tenerse por preparado o admitirse el recurso ante el TS, por ser cuestión que compete alTribunal Superior de Justicia (35).

Reiterando la doctrina sobre la anterior regulación, el recurso de casación estatal no puede fundarse en la infracción de normas de Derecho autonómico, ni cabe eludir dicho obstáculo procesal encubriendo la denuncia de la indebida interpretación y aplicación de normas autonómicas bajo una cita artificiosa y meramente instrumental de normas de derecho estatal (36). Cuando la parte no pretende una revisión o aclaración de la jurisprudencia sobre la incongruencia omisiva, sino que se limita a invocar dicha incongruencia como presupuesto previo para cuestionar la correcta aplicación del ordenamiento autonómico, la cita de los preceptos del ordenamiento estatal relativos a la congruencia de las sentencias se reputa meramente instrumental respecto al fondo de la cuestión debatida que sigue siendo exclusivamente autonómica (37).

La nueva regulación no contempla la compatibilidad y, en su caso, la preferencia entre el recurso de casación estatal y el autonómico. Si la sentencia suscita cuestiones o infracciones de derecho estatal o comunitario europeo y también autonómico, es posible la preparación simultánea o su-

(32) AATS de 3 de abril de 2017 (Rec. Casación 506/2017): precepto de reglamento autonómico de Agentes Forestales en cuanto a color señales luminosas de sus vehículos], de 16 de mayo de 2017 (Rec. Casación 1190/2017: anulación Decreto autonómico sobre jornada laboral del personal funcionario), de 8 de junio de 2017 (Rec. Casación 1718/2017): exigencia de un responsable en todas las estaciones de servicio por reglamento autonómico] y de 26 de junio de 2017 (Rec. Casación 1488/2017: anulación parcial de decreto autonómico sobre material vegetal)

(33) ATS de 24 de mayo de 2017 (Rec. Casación 767/2017). Criterio ya aplicado también a normas tributarias forales idénticas a las estatales, aunque sin explicitar mayor justificación en AATS de 1 de marzo de 2017 (Rec. Casación 28/2017), de 15 de marzo de 2017 (Rec. Casación 163/2016), de 5 de abril de 2017 (Rec. 4004/2017) y de 28 de abril de 2017 (Rec. Casación 76/2017).

(34) ATS de 29 de marzo de 2017 (Rec. Queja 89/2017).

(35) ATS de 26 de abril de 2017 (Rec. Queja 153/2017) y de 26 de junio de 2017 (Rec. Queja 295/2017).

(36) ATS de 26 de junio de 2017 (Rec. Queja 295/2017).

(37) ATS de 17 de julio de 2017 (Rec. Casación num. 1271/2017). 
cesiva de ambas casaciones, siempre que se haga dentro del plazo legalmente establecido, si bien la infracción del ordenamiento estatal ha de referirse a vicios sustantivos y no procedimentales (incongruencia omisiva). La general preferencia del recurso estatal adoptada por las Salas territoriales(38) ha sido matizada por elTS: no es procedente su tramitación simultánea y tiene preferencia la casación estatal cuando las infracciones de normas estatales o comunitarias están referidas a la pretensión principal y la decisión delTS pudiera condicionar el resultado del recurso de casación autonómico y, en cambio, si las infracciones de normas estatales o comunitarias no condicionan el resultado del recurso de casación autonómico, por referirse a la pretensión subsidiaria, debe darse preferencia a la tramitación de la casación autonómica; sin perjuicio de la impugnación a través del recurso de queja ante elTS contra la decisión del órgano de instancia de tener por no preparado o suspender la tramitación de la casación estatal (39).

\section{Legitimación}

Como había señalado la doctrina (40), la jurisprudencia recaída en relación con el artículo 89.3 LJCA, en su inicial redacción, es trasladable a la interpretación del actual art. 89.1 (en la redacción dada por la LO 7/2015), de manera que están habilitados para preparar el recurso de casación quienes hubiesen sido parte o podido serlo en el recurso contencioso-administrativo en que se dictó la resolución impugnada, lo que no supone la exigencia absoluta de haberse personado en él antes de la sentencia, pero sí, desde luego, dentro del plazo legalmente establecido para la preparación del recurso de casación; es decir, basta con que aquella personación, aún posterior a la sentencia, se haya verificado antes de que ésta gane firmeza (41).

\section{El interés casacional objetivo: piedra angular de la nueva casación}

El recurso de casación es el instrumento por excelencia para asegurar la uniformidad en la aplicación judicial del derecho, como se hace constar

(38) Así, AATS de la Sala de lo Contencioso-Administrativo del TSJ de Navarra de 30 de junio de 2017 -y providencia de 8 de septiembre de 2017 (Rec. Contencioso-administrativo 456/2011) y de 4 de julio de 2017 -y providencia de 12 de julio de 2017- (Rec. Contencioso-administrativo 455/2011), acuerdan tener por preparado el recurso de casación estatal y dejan en suspenso la tramitación de la casación autonómica hasta tanto no se resuelva la casación estatal.

(39) ATS de 17 de julio de 2017 (Rec. Casación num. 1271/2017).

(40) Así, RAZQUIN LIZARRAGA, “El recurso...», op. cit. pág. 152.

(41) ATS de 29 de marzo de 2017 (Rec. Queja 142/2017). 
en el preámbulo de la Ley Orgánica 7/2015; y de esta manera elTS sirve al principio de seguridad jurídica y, por su intermediación, al de igualdad en la aplicación de la ley (arts. 9.3 y 14 CE) (42).

La nueva regulación del recurso de casación contencioso-administrativo supone un cambio trascendente al pivotar ahora el sistema sobre la existencia (o no) de un interés casacional objetivo para la formación de jurisprudencia (43), que se erige como la piedra angular del nuevo modelo casacional, al atribuirse alTS como cometido principal fijar la interpretación de aquellas normas estatales o la que tenga por establecida o clara de las de la Unión Europea sobre las que, en el auto de admisión a trámite, se consideró necesario su pronunciamiento (arts. 88.1 y 90.4 LJCA) (44). Por ello, este concepto jurídico indeterminado es el objeto primordial de numerosas resoluciones de la Sección de Admisión, que han intentado precisar su interpretación (45).

La noción de interés casacional objetivo se conforma a partir de tres elementos interdependientes: 1) La enumeración de supuestos en los que podrá apreciarse o se presume la existencia de interés casacional objetivo (art. 88.2 y 3 LJCA) (46); 2) Su obligada referencia o concreción en las infracciones o cuestiones jurídicas suscitadas (47), lo que exige la previa concreción de la cuestión jurídica objeto de casación respecto de

(42) ATS de 1 de febrero de 2017 (Rec. Casación 2/2016), de 20 de febrero de 2017 (Rec. Casación 139/2016), de 2 de marzo de 2017 (Rec. Casación 159/2017), de 20 de julio de 2017 (Rec. Casación 1354/2017) y de 21 de julio de 2017 (Rec. Casación 2022/2017).

(43) ATS de 15 de marzo de 2017 (Rec. Queja 26/2017), de 15 de marzo de 2017 (Rec. Queja 57/2017), de 22 de mayo de 2017 (Rec. Queja 261/2017) y de 24 de mayo de 2017 (Rec. Queja 278/2017).

(44) ATS de 19 de junio de 2017 (Rec. Queja 273/2017). Véanse, además de doctrina citada en nota 1, MESTRE DELGADO, Juan Francisco, "La configuración del recurso de casación en torno al interés casacional», en BAÑO LEÓN, José María (coord.), Memorial para la reforma del Estado: Estudios en homenaje al Profesor Santiago Muñoz Machado, CEPC, Madrid, 2016, vol. 1, págs. 1011-1031; y RECUERDA GIRELA, Miguel Ángel, «El nuevo recurso de casación contencioso-administrativo y el interés casacional objetivo para la formación de la jurisprudencia», en Revista Andaluza de Administración Pública, núm. 94, 2016, págs. 107-150.

(45) Véanse RAZQUIN LIZARRAGA, José Antonio, «El interés casacional objetivo según el Tribunal Supremo», en REDA núm. 188, 2017; y GARCIA CASTRO, David, "El interés casacional objetivo como requisito único a acreditar en los escritos de preparación de recursos de casación ante la Sala 3. ${ }^{a}$ del Tribunal Supremo. Un análisis de la incipiente jurisprudencia de la Sala de Admisión del Alto Tribunal tras la entrada en vigor de la LO 7/2015», en RVAP núm. 109, 2017, págs. 469-493.

(46) ATS de 15 de marzo de 2017 (Rec. Queja 26/2017), de 15 de marzo de 2017 (Rec. Queja 57/2017), de 22 de mayo de 2017 (Rec. Queja 261/2017) y de 24 de mayo de 2017 (Rec. Queja 278/2017).

(47) En palabras del ATS de 21 de marzo de 2017 (Rec. Casación 308/2016), «el recurso de casación articulado en la LO 7/2015, de 21 de julio, persigue como finalidad la formación de jurisprudencia cuando se estime que presenta interés casacional objetivo, pero no en abstracto, sino en relación con la resolución de las cuestiones suscitadas en el pleito que fueron objeto del pronunciamiento en la sentencia o debieran haberlo sido, y ello en cuanto que sigue siendo un recurso extraordinario para la tutela de los derechos subjetivos hechos valer por las partes en el proceso". 
la que se ponderará la concurrencia de tal interés (48); y 3) Su finalidad estriba en la formación de jurisprudencia (art. 88.1 LJCA) (49), primando ese carácter objetivo sobre el subjetivo (intereses del recurrente) (50).

\section{Circunstancias ejemplificativas}

El primer listado es abierto y contiene nueve circunstancias indiciarias o ejemplificativas de interés casacional objetivo (art. 88.2 LJCA), que se interpretan del modo siguiente:

a) Doctrina contradictoria con la de otros órganos jurisdiccionales: exige la contradicción entre la sentencia recurrida y la dictada por otros órganos jurisdiccionales en las cuestiones planteadas sobre interpretación de normas del Derecho estatal o comunitario europeo (51), respecto de cuestiones que sean sustancialmente iguales, esto es, en casos idénticos, iguales o análogos a la resolución recurrida (52). Esta circunstancia opera cuando se aprecia la existencia de disparidades o contradicciones insalvables entre las sentencias sometidas a contraste, en cuanto concierne a la interpretación de las mismas normas y en relación con un problema de interpretación y aplicación sustancialmente coincidente(53). Las sentencias de contraste han de ser firmes (54) y pueden proceder de cualquier juzgado o tribunal, incluido el TS (55), no sólo del orden contencio-

(48) Por todos, ATS de 17 de mayo de 2017 (Rec. Casación 255/2016).

(49) Como señala, por todos, el ATS de 19 de junio de 2017 (Rec. Queja 273/2017), el recurso de casación contencioso-administrativo presenta una decidida vocación de erigirse como un instrumento procesal volcado en la labor hermenéutica del Derecho Público, administrativo y tributario, con el objetivo de proporcionar certeza y seguridad jurídica en la aplicación de este sector del Ordenamiento.

(50) Así el ATS de 14 de junio de 2017 (Rec. Casación 635/2017) declara que, en razón de la singularidad de las circunstancias concurrentes, el asunto carece manifiestamente de interés casacional objetivo para la formación de la jurisprudencia, por nítido que sea el interés casacional subjetivo de la entidad recurrente.

(51) ATS 8 de febrero de 2016 (Rec. Casación 206/2016).

(52) ATS de 1 de marzo de 2017 (Rec. Casación 128/2016).

(53) AATS de 7 de febrero de 2017 (Rec. Casación 161/2016) y de 27 de marzo de 2017 (Rec. Casación 377/2017).

(54) ATS de 8 de marzo de 2017 (Rec. Casación 40/2017).

(55) Así, ATS de 20 de julio de 2017 (Rec. Casación 2093/2017) respecto de sentencias de Juzgados; AATS de 21 de julio de 2017 (Rec. Casación 2944/2017) y de 21 de julio de 2017 (Rec. Casación 2878/2017) con sentencias de otras Salas territoriales; y AAATS de 12 de julio de 2017 (Rec. Casación 2220/2017), de 20 de julio de 2017 (Rec. Casación 299/2016) y de 21 de julio de 2017 (Rec. Casación 2112/2017) con sentencias de la Sala 3. ${ }^{\text {a }}$ delTS. 
so-administrativo sino también de otros órdenes (civil y social) (56), pero no del mismo órgano jurisdiccional (57).

b) Doctrina gravemente dañosa para el interés general: su apreciación debe atender de forma prioritaria a la virtualidad expansiva de la doctrina sentada por la sentencia recurrida, procediendo la inadmisión si no resulta diáfana ni se concreta, más allá del nítido interés subjetivo de ésta (58) y exige que la doctrina de la sentencia recurrida sea errónea (59). Esta circunstancia puede ser alegada por las Administraciones públicas (60) y también por los particulares recurrentes(61).

c) Afectación a gran número de situaciones o trascendencia general: depende de la concreta cuestión considerada y exige bien que la doctrina recurrida pueda afectar a un gran número de situaciones, trascendiendo al caso objeto del proceso (62) o bien que la jurisprudencia que pueda fijar el TS sea susceptible de aplicación por los operadores jurídicos (administraciones públicas y órganos de la jurisdicción contencioso-administrativa) a situaciones iguales (63).

d) Resolución de debate sobre la validez constitucional de norma legal sin esclarecer suficientemente la improcedencia de plantear cuestión de inconstitucionalidad: se aprecia si en el proceso se ha debatido sobre la validez constitucional de una ley, sin que pueda afirmarse que sea manifiestamente improcedente el planteamiento de la cuestión de constitucionalidad(64) o ha existido debate en la instancia sobre la procedencia de plantear la cuestión de inconstitucionalidad y existían dudas legales a la vista de la doctrina constitucional sin que la sentencia diese respuesta alguna a la petición(65).

(56) AATS de 8 de marzo de 2017 (Rec. Casación 40/2017), de 21 de marzo de 2017 (Rec. Casación 98/2017), de 11 de abril de 2017 (Rec. Casación 577/2017), de 19 de junio de 2017 (Rec. Queja 346/2017) y de 26 de junio de 2017 (Rec. Casación 1134/2017). En este sentido, HUELíN MARTíNEZ DE VELASCO, op. cit.

(57) ATS de 7 de junio de 2017 (Rec. Casación 997/2017).

(58) ATS de 1 de febrero de 2017 (Rec. Casación 31/2016).

(59) AATS de 24 de mayo de 2017 (Rec. Casación 235/2016) y de 12 de julio de 2017 (Rec. Casación 2800/2017).

(60) AATS de 21 de marzo de 2017 (Rec. Casación 209/2016), de 24 de mayo de 2017 (Rec. Casación 235/2016) y de 12 de julio de 2017 (Rec. Casación 2800/2017).

(61) AATS de 27 de marzo de 2017 (Rec. Casación 263/2017), 3 de abril de 2017 (Rec. Casación 480/2017), de 22 de mayo de 2017 (RCA 1018/2017) y de 7 de junio de 2017 (Rec. Casación 997/2017).

(62) AATS 8 de febrero de 2017 (Rec. Casación 86/2016) y de 12 de julio de 2017 (Rec. Casación 1985/2017).

(63) ATS 1 de febrero de 2016 (Rec. Casación 2/2016).

(64) ATS de 3 de febrero de 2017 (Rec. Casación 203/2016).

(65) ATS de 3 de febrero de 2017 (Rec. Casación 319/2017). 
e) Interpretación y aplicación aparentemente errónea y determinante de doctrina constitucional: concurre cuando se alega la interpretación y aplicación errónea de una sentencia constitucional (66) o cuando la sentencia recurrida se refiere a la interpretación y aplicación de la doctrina constitucional sobre un derecho fundamental (67).

f) Interpretación y aplicación del derecho comunitario en contradicción aparente con jurisprudencia del TJUE o en supuestos que puedan exigir su intervención a título prejudicial: se aprecia si la resolución impugnada aplica el Derecho europeo en contradicción aparente con la jurisprudencia del Tribunal de Justicia y aborda un supuesto en que pudiera ser exigible la intervención de dicho Tribunal a título prejudicial (68), lo que es frecuente en temas tributarios por su armonización directa o por la incidencia del derecho comunitario europeo (69).

g) Impugnación directa o indirecta de disposición general: se refiere a la impugnación de cualquier acto de naturaleza normativa(70), sin que requiera su anulación pues ello conforma una presunción [art. 88.3.c) LJCA].

h) Convenio entre Administraciones públicas: se refiere a un proceso concerniente a un convenio interadministrativo(71).

i) Resolución dictada en procedimiento especial de protección de derechos fundamentales: concurre cuando la sentencia se ha dictado en un procedimiento especial para la protección de los derechos fundamentales (72).

Este listado tiene carácter abierto («entre otras circunstancias»), por lo que puede invocarse y estimarse existente el interés casacional objetivo del recurso por otros supuestos distintos no especificados en los apartados 2 y 3 del art. 88, pero, dada su excepcionalidad, se exige una especial justificación en el escrito de preparación (73).

(66) ATS de 7 de junio de 2017 (Rec. Casación 1309/2017).

(67) ATS de 25 de abril de 2017 (Rec. Casación 299/2017).

(68) ATS de 27 de febrero de 2017 (Rec. Casación 27/2016).

(69) ATS de 28 de junio de 2017 (Rec. Casación 1884/2017).

(70) ATS de 9 de junio de 2017 (Rec. Casación 1804/2017) y de 19 de junio de 2017 (Rec. Casación 1476/2017).

(71) ATS de 16 de mayo de 2017 (Rec. Casación 922/2017) y de 16 de mayo de 2017 (Rec. Casación 720/2017).

(72) ATS de 25 de abril de 2017 (Rec. Casación 299/2017), de 25 de abril de 2017 (Rec. Casación 393/2017), de 25 de abril de 2017 (RCA 299/2017) y de 26 de junio de 2017 (Rec. Casación 1578/2017).

(73) AATS de 15 de marzo de 2017 (Rec. Casación 91/2017), de 15 de marzo de 2017 (Rec. Casación 93/2017) y de ATS de 7 de junio de 2017 (Rec. Casación 305/2017). 


\section{Presunciones}

El segundo listado expresa cinco presunciones y se cierra con una excepción para tres de ellas (art. 88.3 LJCA). Son las siguientes:

a) Inexistencia de jurisprudencia sobre la cuestión: exige que las normas o cuestiones que constituyen la razón de decidir de la sentencia recurrida no hayan sido interpretadas por el TS (74) o se trate de una cuestión específica o situación distinta inédita en la jurisprudencia del TS(75), por lo que no concurre si existe jurisprudencia sobre las cuestiones planteadas (76), salvo que aquella no resuelve la concreta cuestión planteada en el recurso (77). La inexistencia no se entiende en términos absolutos, sino relativos, por lo que concurre, no solo cuando no existe jurisprudencia, sino también si es necesario matizarla, precisarla o concretarla para realidades jurídicas diferentes a las ya contempladas en esa jurisprudencia (78); pero no se refiere a la falta de una resolución específica que resuelva un supuesto singular idéntico en sus aspectos fácticos al que se recurra en cada momento ante el TS (79). Es una presunción iuris tantum (art. 88.3 in fine LJCA) (80).

b) Apartamiento deliberado de la jurisprudencia por considerarla errónea: es una presunción iuris et de iure cuya alegación impone la admisión (81), que requiere que el apartamiento sea deliberado y que la razón estribe en considerar errónea la jurisprudencia, pues la separación debe ser voluntaria, intencionada y hecha a propósito

(74) ATS 1 de febrero de 2017 (Rec. Casación 36/2016), de 10 de mayo de 2017 (Rec. Casación 812/2017), de 21 de junio de 2017 (Rec. Casación 1101/2017) y de 6 de julio de 2107 (Rec. Casación 1677/2017).

(75) AATS 1 de febrero de 2017 (Rec. Casación 2/2016), de 8 de febrero de 2017 (Rec. Casación 22/2016), de 27 de marzo de 2017 (Rec. Casación 9/2017), de 29 de marzo de 2017 (Rec. Casación 496/2017), de 14 de junio de 2017 (Rec. Casación 1443/2017), de 10 de abril de 2017 (Rec. Casación 953/2017), de 28 de abril de 2017 (Rec. Casación 839/2017), de 3 de mayo de 2017 (Rec. Casación 481/2017) y 31 de mayo de 2017 (Rec. Casación 1094/2017).

(76) AATS de 15 de marzo de 2017 (Rec. Casación 93/2017) y de 10 de abril de 2017 (Rec. Casación 225/2017).

(77) AATS de 2 de marzo de 2017 (Rec. Casación 159/2017) y de 29 de mayo de 2017 (Rec. Casación 1121/2017).

(78) ATS de 15 de marzo de 2017 (Rec. Casación 93/2017) y de 21 de junio de 2016 (Rec. Casación 1983/2017).

(79) AATS de 25 de enero de 2017 (Rec. Casación 15/2016), de 22 de marzo de 2017 (Rec. Casación 218/2016), de 5 de abril de 2017 (RC 99/2017) y de 12 de junio de 2017 (Rec. Casación 1115/2017).

(80) ATS de 13 de marzo de 2017 (Rec. Casación 8/2017).

(81) AATS de 10 de mayo de 2017 (Rec. Casación 1150/2017) y de 11 de abril de 2017 (Rec. Casación 595/2017). 
porque el juez de la instancia considera equivocada la jurisprudencia (82).

c) Sentencia que declara nula una disposición general: se considera una presunción iuris et de iure al no serle aplicable la excepción del art. 88.3 in fine LJCA (83); pero es precisa la concurrencia acumulativa de dos condiciones: la anulación de un acto de naturaleza normativa y que ésta no carezca manifiestamente de trascendencia suficiente (84).

d) Recurso contra actos o disposiciones de organismos reguladores o de supervisión o agencias estatales de la competencia de la Audiencia Nacional: sólo opera respecto de las sentencias dictadas por ésta en única instancia y no en apelación (85). Esta presunción no tiene carácter absoluto (art. 88.3 in fine LJCA), siendo excepcionada en muchos casos (sanciones) por su carácter casuístico o falta de generalidad (86).

e) Recurso contra actos o disposiciones de los Gobiernos o Consejos de Gobierno de las Comunidades Autónomas: esta presunción tampoco es absoluta (art. 88.3 in fine LJCA) (87) y se refiere a resoluciones en procesos de impugnación de actuaciones que proceden de los Gobiernos o Consejos de Gobierno de las Comunidades Autónomas (88).

Las presunciones de las letras a), d) y e) no son absolutas, pues cabe inadmitir mediante auto motivado los recursos inicialmente beneficiados por aquellas si el TS aprecia que el asunto carece manifiestamente de interés casacional objetivo para la formación de jurisprudencia (úl-

(82) AATS de 8 de marzo de 2017 (Rec. Casación 40/2017) y de 10 de mayo de 2017 (Rec. Casación 1150/2017).

(83) AATS de 3 de abril de 2017 (Rec. Casación 506/2017), de 16 de mayo de 2017 (Rec. Casación 692/2017), de 16 de junio de 2017 (Rec. Casación 710/2017) y de 21 de junio de 2017 (Rec. Casación 1800/2017).

(84) AATS de 20 de febrero de 2017 (Rec. Casación 111/2016), de 13 de marzo de 2017 (Rec. Casación 315/2016), de 3 de mayo de 2017 (Rec. Casación 189/2017), de 16 de mayo de 2017 (Rec. Casación 692/2017), de 7 de junio de 2017 (Rec. Casación 1394/2017); de 7 de junio de 2017 (Rec. Casación 1086/2017), de 16 de junio de 2017 (Rec. Casación 710/2107), de 21 de junio de 2017 (Rec. Casación 1193/2017) y de 12 de julio de 2017 (Rec. Casación 1917/2017).

(85) ATS de 18 de abril de 2017 (Rec. Casación 114/2016). Véase la crítica a este auto de GONZÁLEZ LÓPEZ, Arantza, "Interés casacional objetivo: actos o disposiciones de organismos reguladores o de supervisión o agencias estatales. Interpretación del artículo 88.3.d) LJCA», en Actualidad Administrativa núm. 9, 2017.

(86) AATS de 6 de marzo de 2017 (Rec. Casación 150/2016) y de 24 de abril de 2017 (Rec. Casación 611/2017).

(87) ATS de 4 de julio de 2017 (Rec. Casación 1461/2017).

(88) AATS de 26 de junio de 2017 (Rec. Casación 1488/2017) y de 4 de julio de 2017 (Rec. Casación 1461/2017). 
timo párrafo del art. 88.3 LJCA)(89). Esta excepción se interpreta del modo siguiente: $1 .^{\circ}$ ) Por "asunto" ha de entenderse no tanto el tema litigioso de la instancia, globalmente considerado, sino más bien la concreta cuestión planteada en el escrito de preparación por referirse a ella el juicio sobre el interés casacional que justifica la admisión del recurso; y $2^{\circ} .^{\circ}$ El adverbio "manifiestamente» implica que la carencia de interés ha de ser claramente apreciable sin necesidad de complejos razonamientos o profundos estudios del tema litigioso. Así, a título de ejemplo, el recurso podría ser inadmitido si se pretende anudar el interés casacional a infracciones normativas circunscritas a las concretas vicisitudes del caso sin trascender a cuestiones dotadas de un mayor contenido de generalidad o con posible proyección a otros litigios; o si las planteadas en el caso son cuestiones que han sido ya abordadas y resueltas por la jurisprudencia consolidada, sin que se aporten argumentos sólidos en pro de una reconsideración o cambio de la jurisprudencia asentada sobre dicha cuestión (90).

\section{Presupuesto básico: formación de jurisprudencia}

La formación de jurisprudencia constituye el presupuesto básico e inexcusable de la noción de interés casacional objetivo según resulta del juego combinado de los arts. 88.1 y 89.2.f), in fine, LJCA, operando como exigencia adicional o complementaria a cumplimentar en el escrito de preparación; por lo que no basta que el asunto presente interés casacional objetivo, sino que ha de serlo también para la formación de jurisprudencia (91).

Por ello, la cuestión planteada, amén de situarse en el escenario del art. 88.2.a) LJCA, debe en todo caso revestir indudable interés objetivo para la formación de la jurisprudencia (art. 88.1 LJCA), pues la contradicción alegada exterioriza un problema interpretativo del ordenamiento jurídico que necesita ser clarificado y resuelto por elTS, a fin de reconducir la disparidad hermenéutica y, así, garantizar la certeza y la seguridad jurí-

(89) ATS de 25 de mayo de 2017 (Rec. Casación 854/2017).

(90) AATS de 4 de abril de 2017 (Rec. Casación 331/2017), de 25 de mayo de 2017 (Rec. Casación 854/2017) y de 26 de junio de 2017 (Rec. Casación); en ocasiones sin pronunciarse expresamente sobre la excepción (ATS de 12 de julio de 2017, Rec. Casación 2173/2017) o de forma implícita al concurrir simultáneamente el supuesto del art. 88.2.c) [así, AATS de 3 de abril de 2017 (Rec. Casación 78/2017), de 12 de julio de 2017 (Rec. Casación 1180) y de 20 de julio de 2017 (Rec. 2203/2017)].

(91) En este sentido, RAZQUIN LIZARRAGA, “El recurso...», op. cit., págs. 144-147; QUINTANA CARRETERO y otros, op. cit., págs. 25 y 141-149; y HUELÍN MARTíNEZ DE VELASCO, op. cit. Por su parte, VELASCO CABALLERO, op. cit., § 58, señala que es la finalidad directa, pero no única, de la nueva casación contenciosa. 
dica en la interpretación y aplicación del Derecho(92). La concurrencia de una presunción [art. 88.3.a)] no es suficiente si la cuestión carece de la nota de generalidad que haga conveniente y justifique una decisión del TS (93) o existe ya una consolidada jurisprudencia sobre la cuestión controvertida establecida con carácter general (94).

La actualización o reconsideración de la jurisprudencia justifica la conveniencia de pronunciamiento del TS, por ser tarea propia del recurso de casación, que no sólo debe operar para formar la jurisprudencia ex novo, sino también para matizarla, precisarla o, incluso, corregirla (95). Asimismo, la existencia de una única sentencia del TS no enerva la concurrencia del interés casacional objetivo, pues hace aconsejable - para formar jurisprudencia mediante la doctrina reiterada a la que se refiere el artículo $1.6 \mathrm{del}$ Código Civil- que la Sala se pronuncie para reafirmar, reforzar o completar aquel criterio o, en su caso, para cambiarlo o corregirlo (96).

\section{Los vicios procedimentales en el nuevo recurso de casación}

En la regulación precedente era frecuente la alegación de infracciones de carácter procesal, existiendo una consolidada jurisprudencia, en particular sobre la incongruencia omisiva. Esa situación ha sufrido una profunda mutación a consecuencia de la nueva lógica casacional, mostrando la difícil viabilidad de las infracciones procedimentales en la nueva casación (97).

\section{Incongruencia omisiva: exigencia de un nuevo trámite para acceder a la casación}

Aunque la nueva regulación, en línea continuista, exige para los vicios procesales la acreditación en el escrito de preparación de que se produjo indefensión y se pidió la subsanación de haber sido posible [art. 89.2.c) LJCA], este requisito ha sido trastocado al crearse un nuevo trámite que debe cumplimentarse previamente por la parte recurrente.

(92) AATS de 7 de febrero de 2017 (Rec. Casación 161/2016), de 5 de abril de 2017 (Rec. Casación 196/2017) y de 10 de abril de 2017 (Rec. Casación 981/2017).

(93) ATS de 7 de junio de 2017 (Rec. Casación 305/2017).

(94) AATS de 20 de febrero de 2017 (Recs. Casación 111/2016 y 118/2016).

(95) AATS de 15 de marzo de 2017 (Rec. Casación 93/2017), de 26 de abril de 2017 (Rec. Casación 680/2017) y de 24 de mayo de 2017 (Rec. Casación 678/2017).

(96) ATS de 10 de julio de 2017 (Rec. Casación 1840/2017) y de 20 de julio de 2017 (Rec. Casación 2483/2017).

(97) Así lo había advertido RAZQUIN LIZARRAGA, «Problemas...», op. cit., págs. 58-59. 
Conforme a lo dispuesto en el art. 89.2.c) LJCA, cuando la única o exclusiva razón esgrimida en casación sea la incongruencia omisiva, se exige novedosamente acreditar, como presupuesto de procedibilidad, haber instado antes sin éxito el complemento de la sentencia por el cauce previsto en los arts. 267.5 LOPJ y 215.2 LEC (98).

\section{Escasa viabilidad y carácter accesorio de las infracciones de carácter procesal}

La admisión de una cuestión referida a una infracción procedimental (incongruencia) será excepcional por ser infrecuente que la parte recurrente pretenda una revisión o aclaración de la jurisprudencia sobre la incongruencia omisiva, al existir una abundante y reiterada jurisprudencia sobre ella, por lo que difícilmente serán necesarios nuevos pronunciamientos del TS. Casi siempre se invoca la incongruencia como presupuesto previo para cuestionar la correcta aplicación del ordenamiento sustantivo y en tales casos debe referirse precisamente a una cuestión de fondo que presente interés casacional objetivo para la formación de jurisprudencia y se invoquen como infringidos, por su inaplicación, los preceptos que la disciplinan (99).

La alegación en casación de "vicios in procedendo" tiene por sí sola escasa o nula virtualidad, ya que es preciso acreditar, no sólo que tales vicios se han producido efectivamente, sino también que esas infracciones procedimentales o formales han repercutido en un deficiente análisis de una cuestión sustantiva que está dotada de interés casacional(100).

(98) AATS de 1 de marzo de 2017 (Rec. Casación 88/2016). Doctrina reiterada en AATS de 15 de febrero de 2017 -sorprendentemente, por ser anterior- (Rec. Queja 157/2016); de 22 de marzo de 2017 (Rec. Casación 49/2017), de 29 de marzo de 2017 (Rec. Casación 159/2016) y de 5 de abril de 2017 (Rec. Casación 471/2017). Esta novedad sobre el sistema anterior se justifica en varias razones: la funcionalidad de dicho incidente para integrar o completar la sentencia, sin que sea lógico permitir que se abra un trámite para obtener respuesta sobre aquello a lo que no se contestó, que luego carece de incidencia en la situación jurídica de quien insta el complemento; tal exigencia previa no es un obstáculo formal desproporcionado, sino que redunda en una mayor y efectiva protección de los derechos e intereses legítimos al permitir la integración de la sentencia incompleta por el órgano de instancia sin necesidad de afrontar los costes económicos y temporales inherentes a un recurso de casación y ahorrar un recorrido procesal que puede resultar desalentador por la difícil concurrencia del interés casacional objetivo ante la existencia de jurisprudencia sobre la cuestión y tortuoso por el peregrinaje jurisdiccional (recurso de casación y nulidad de actuaciones previo al amparo constitucional), por lo que tal exigencia previa viene a reforzar los derechos procesales de los litigantes y redunda en una mayor agilidad y eficacia del trámite procesal de admisión de los recursos de casación preparados.

(99) AATS de 31 de mayo de 2017 (Rec. Casación 1122/2017) y de 17 de julio de 2017 (Rec. Casación 1271/2017).

(100) AATS de 21 de marzo de 2017 (Rec. Casación 308/2016) y de 12 de julio de 2017 (Rec. Queja 58/2017) 
Por tanto, las infracciones procesales han perdido sustantividad propia y tiene carácter accesorio de la cuestión sustantiva planteada. Únicamente operan cuando se alegan junto a otros supuestos de interés casacional objetivo por referirse a una pretensión de fondo que presente dicho interés objetivo para la formación de la jurisprudencia(101). Así la incongruencia omisiva sólo tiene interés casacional si lo tiene la cuestión jurídica que no ha sido abordada(102).

La infracción procesal denunciada trasciende al caso cuando repercuta en la aplicación (incongruencia omisiva o por error) de una norma de cuya interpretación y alcance se invoca y justifica interés casación objetivo se ponderará en la admisibilidad y se incluye en la fijación de la cuestión admitida(103). Es correcta la decisión de no tener por preparado el recurso si se denuncia de una falta de motivación o una incongruencia omisiva, pero no se da el paso añadido de argumentar cómo o en qué medida esa omisión de examen y pronunciamiento ha incidido en una cuestión interpretativa del ordenamiento que de por sí ostenta interés casacional objetivo para la formación de la jurisprudencia, sin que sea útil la invocación de la jurisprudencia general sobre la relevancia de la actividad probatoria o sobre la necesidad de motivación y congruencia de las resoluciones judiciales, pues esa doctrina jurisprudencial realmente no se discute en este caso, en el que lo que se pone en juego es simplemente su proyección casuística sobre el litigio aquí concernido(104).

De ahí que el interés casacional objetivo no pueda apreciarse en la casación estatal cuando el pronunciamiento de fondo omitido versa sobre el derecho autonómico, al quedar éste al margen del enjuiciamiento que corresponde alTS(105).

Por otra parte, es posible, como en el sistema anterior, la integración en los hechos admitidos como probados por la sentencia (art. 93.3 LJCA), que puede llevarse a cabo incluso en el trámite de admisión(106).

(101) Por todos, ATS de 1 de marzo de 2017 (Rec. Casación 88/2016).

(102) ATS de 19 de junio de 2017 (Rec. Queja 273/2017).

(103) ATS de 21 de marzo de 2017 (Rec. 308/2016) y de 16 de mayo de 2017 (Rec. Casación 1190/2017).

(104) ATS de 12 de julio de 2017 (Rec. Queja 58/2017).

(105) ATS de 17 de julio de 2017 (Rec. Casación 1271/2017), en el que, previamente, se dice: «El principio de congruencia de las resoluciones constituye un principio común para todos los ordenamientos jurídicos, ya sea el estatal, autonómico o local, sin que su mera invocación pueda servir de base por si solo para fundar un recurso de casación estatal, cuando el derecho material desconocido o inaplicado es puramente autonómico, pues admitir lo contrario sería tanto como privar de contenido al artículo 86.3 de la Ley Jurisdiccional, al existir siempre la posibilidad de acogerse a estos preceptos instrumentales y principios generales para con base en su infracción entablar el recurso de casación".

(106) ATS de 26 de abril de 2017 (Rec. Casación 680/2017). 


\section{Impacto sobre el incidente de nulidad de actuaciones}

El incidente de nulidad de actuaciones ha sido derechamente afectado en razón de la recurribilidad cuasi universal en casación de las sentencias - con el límite indicado para las dictadas en única instancia por los Juzgados - . El nuevo sistema casacional supone, en principio, la exclusión en tales casos del incidente del nulidad de actuaciones en razón de su carácter subsidiario de impugnación de resoluciones firmes (art. 241.1 LOPJ), al ser potencialmente susceptibles de recurso de casación todas las sentencias, aunque su admisión sea altamente improbable por dirigirse, más que a la formación de jurisprudencia, a la aplicación de la abundante doctrina existente a las circunstancias del caso (107).

Para evitar que con el nuevo sistema el operador jurídico se encuentre, en caso de infracciones de normas procesales y de resoluciones potencialmente susceptibles de casación, prácticamente huérfano de remedio efectivo, se ha propuesto la necesidad de flexibilizar la admisión del incidente de nulidad de actuaciones en los casos de las resoluciones impugnables en casación en la instancia (admitiendo el recurso si se razona la improbable admisión de la casación) o en elTS (bien se entienda que la inadmisión reabre el plazo para el incidente o bien en la inadmisión se prevea la retroacción de actuaciones para formular el incidente) (108).

En las Salas de los Tribunales inferiores no existe unidad de criterio: una no cuestiona la admisión del incidente de nulidad de actuaciones planteado, por incongruencia omisiva, contra sentencia dictada bajo la vigencia de la nueva regulación, aunque resulta desestimado (109); pero otra niega la incoación del incidente de nulidad de actuaciones ya que la sentencia discutida no es firme al ser susceptible de recurso de casación según se indicó al notificarse la sentencia definitiva(110).

Finalmente, el TS ha dado una solución para esta específica cuestión, considerando que la anterior doctrina respecto de la incongruencia omisiva (previo planteamiento de un incidente de complemento o

(107) RAZQUIN LIZARRAGA, "Problemas...", cit., págs. 58-59; QUINTANA CARRETERO y otros, op. cit., págs. 155-160; y TRIANA REYES, Belén, "¿Qué hacer antes de ir al amparo: recurso de casación contencioso o nulidad de actuaciones?", Diario La Ley, N. ${ }^{\circ} 8929$, de 24 de febrero de 2017.

(108) CARCER MINCHOT, Pilar, «Nulidad de actuaciones y recurso de casación contencioso-administrativo", en 'www.abogacía.es'.

(109) Auto de la Sala de lo Contencioso-Administrativo (Sección 4. ${ }^{\text {a) }}$ de la AN núm. 81/2017, de 24 de marzo de 2017 (Rec. 11/2015).

(110) Providencia de 6 de febrero de 2017, de la Sala de lo Contencioso-Administrativo del TSJ de Navarra (Rec. Contencioso-administrativo 455/2011). 
integración de la sentencia) no es aplicable cuando el vicio imputado es la incongruencia "interna» y "extrapetita» y declarando que en estos supuestos el plazo para interponer el incidente de nulidad de actuaciones se computa desde la notificación de la resolución de inadmisión del recurso de casación, ya que sólo cuando se haya decidido la inadmisión del recurso de casación se podrá afirmar que contra la resolución judicial impugnada no cabe recurso ordinario ni extraordinario (111).

\section{Preparacion del recurso de casación}

\section{Esencialidad y rigor del escrito de preparación: requisitos, insubsanabilidad y forma}

El escrito de interposición es una pieza clave de la nueva regulación(112). En la nueva lógica casacional el escrito de preparación del recurso de casación ante el órgano judicial de instancia adquiere un papel esencial o decisivo como anuncio de las infracciones que se desarrollarán en el escrito de interposición del mismo y la justificación o argumentación de la concurrencia de ese interés casacional objetivo (113).

El art. 89.2 LJCA establece ahora una regulación pormenorizada de los requisitos formales y materiales que debe reunir el escrito de preparación del recurso de casación, cuyo cumplimiento es objeto de un escrutinio formal, estricto y riguroso por elTS, que ha perfilado incluso pautas específicas para satisfacer algunos de ellos. La defectuosa o indebida preparación del recurso por incumplirse cualquiera de tales requisitos - sobre todo, la letra f) - impide el acceso al recurso bien por no tenerlo por preparado o bien por acordarse su inadmisión (114).

Al igual que en la regulación precedente, el incumplimiento en el escrito de preparación de los requisitos legales (falta de argumentación su-

(111) ATS de 11 de diciembre de 2017 (Rec. Casación 3711/2017).

(112) Véase RAZQUIN LIZARRAGA, José Antonio, «El escrito de preparación del nuevo recurso de casación contencioso-administrativo", en Revista Aranzadi Doctrinal núm. 8, 2016, págs. 53-74; MEDIAVILLA CABO, José Vicente, "Los escritos de preparación e interposición del nuevo recurso de casación contencioso-administrativo", en REDA núm. 179/2016, págs. 425-453; y PENÍN ALEGRE, Clara, "La preparación del recurso de casación: un control escurridizo", en Revista Jurídica de Castilla y León, núm. 40, 2016, págs. 1-27.

(113) AATS de 15 de marzo de 2017 (Rec. Queja 26/2017), de 15 de marzo de 2017 (Rec. Queja 57/2017) y de 22 de mayo de 2017 (Rec. Queja 261/2017).

(114) Por todos, AATS de 22 de febrero de 2017 (Rec. Queja 160/2016) y de 22 de mayo de 2017 (Rec. Queja 261/2017). 
ficiente y específica del interés casacional objetivo) no es subsanable en actuaciones posteriores, siendo extemporánea su invocación en el recurso de queja (115).

El escrito de preparación debe ajustarse a la forma señalada en el inciso inicial del art. 89.2 LJCA (apartados separados epigrafiados), pero, a falta de cobertura legal en este caso, los criterios orientadores para los escritos de preparación del recurso de casación fijados en el "Acuerdo sobre la extensión máxima y otras características extrínsecas de los escritos procesales referidos al recurso de casación" de la Sala de Gobierno del TS, de 20 de abril de 2016 son recomendaciones (116), por lo que su falta de cumplimentación constituye un simple defecto de forma susceptible de subsanación(117) y no cabe una interpretación rigorista con un resultado desproporcionado sin que pueda anudarse la denegación de la preparación del recurso de casación al no seguimiento (no aportación de carátula) de unos criterios que se configuran como orientadores (118).

La estructura y contenido del escrito de admisión deriva de la obligación de satisfacer tales requisitos (art. 89.2 LJCA) y se refleja en las decisiones delTS sobre la admisión del recurso que en muchos casos, salvo apreciación apodíctica(119), explicitan en su fundamento primero la verificación de su cumplimiento con referencia a los aspectos siguientes: 1) El escrito se presentó en plazo, la resolución contra la que se dirige el recurso es susceptible de casación y la parte recurrente se encuentra legitimada para interponerlo; 2) En el escrito de preparación se acredita el cumplimiento de tales requisitos reglados, en particular el relativo a la recurribilidad de la resolución judicial impugnada, se identifican con precisión las normas del ordenamiento jurídico estatal que se consideran infringidas y se justifica que las infracciones que se le imputan han sido relevantes para adoptar el fallo impugnado; 3) El escrito de preparación fundamenta especialmente que concurre interés casacional objetivo para la formación de la jurisprudencia porque la sentencia discutida se encuadra en alguno de los supuestos de los apartados 2 y 3 del

(115) ATS de 29 de marzo de 2017 (Rec. Queja 135/2017) y de de 22 de junio de 2017 (Rec. Queja 362/2017).

(116) Publicado en BOE núm. 162, de 6 de julio de 2016.

(117) ATS de 12 de junio de 2017 (Rec. Queja 255/2017).

(118) ATS de 29 de mayo de 2017 (Rec. Queja 254/2017) y de 4 de julio de 2017 (Rec. Queja 301/2017).

(119) En otros, los AATS de 16 de mayo de 2017 (Rec. Casación 846/2017) y de 29 de mayo de 2017 (Rec. Casación 1186/2017) se limitan a decir como inciso inicial del primer razonamiento jurídico: "Cumplidas en el escrito de preparación las exigencias que impone el art. 89.2 de la LJCA». 
art. 88 LJCA; y 4) De los razonamientos de la parte recurrente se infiere la conveniencia de un pronunciamiento de la Sala de lo ContenciosoAdministrativo delTS (120).

\section{Cumplimiento de los requisitos reglados: recurribilidad de las resoluciones}

El cumplimiento de los requisitos reglados - plazo, legitimación y recurribilidad - [art. 89.2.a) LJCA] adquiere especial relevancia cuando se pretenden impugnar resoluciones cuyo acceso a la casación es limitado, pues debe acreditarse la concurrencia de las condiciones exigidas para su recurribilidad.

La limitada recurribilidad de las sentencias dictadas en única instancia por los Juzgados (art. 86.1, párrafo segundo, LJCA) comporta la carga específica de argumentar en el escrito de preparación, de un lado, que la doctrina contenida en la resolución que se impugna puede ser gravemente dañosa para los intereses generales (trascendiendo así de un interés meramente particular) y, de otro, que se trata de una resolución susceptible de extensión de efectos según lo previsto en el art. 110 LJCA(121). La parte recurrente debe satisfacer este requisito con especial diligencia (acreditando que el caso concreto se da un supuesto de doctrina gravemente dañosa para los intereses generales)(122), sin que sea suficiente la simple mención de la concurrencia de esas dos circunstancias (prácticamente mediante una cita literal del art. 86.1 LJCA) sin argumentación alguna al respecto (123).

Respecto de los autos de las Salas debe justificarse en el escrito de preparación que pertenecen a una de las cinco clases en que son recurribles (art. 87.1 LJCA), ya que en otro caso - auto sobre la competencia objetiva del tribunal - no cabe la casación (124). Para ello basta que el recurrente se acoja a cualquiera de tales supuestos alegando que el auto recurrido es de una de las clases (de ejecución) del art. 87.1 LJCA; cuya verificación corresponde alTS, aunque ello no impide que si la Sala de instancia aprecia de manera evidente que el Auto que se pretende recurrir en casación no encaja en ninguna de ellas pueda denegar la preparación del recurso(125).

(120) Por todos, ATS de 17 de mayo de 2017 (Rec. Casación 255/2017).

(121) AATS de 27 de febrero de 2017 (Rec. Queja 36/2017), de 5 de abril de 2017 (Rec. Queja 42/2017), de 30 de mayo de 2017 (Rec. Queja 265/2017) y de de 10 de julio de 2017 (Rec. Queja 112/2017).

(122) ATS de 8 de marzo de 2017 (Rec. Queja 41/2017).

(123) ATS de 15 de febrero de 2017 (Rec. Queja 120/2016).

(124) ATS de 19 de junio de 2017 (Rec. Queja 345/2017) y de 26 de junio de 2017 (Rec. Queja 342/2017).

(125) ATS 15 de marzo de 2017 (RCA 66/2017) y de 5 de abril de 2017 (Rec. Queja 68/2017). 


\section{Identificación de las normas o jurisprudencia, juicio de relevancia y justificación de su carácter estatal o comunitario}

Tres requisitos del escrito de preparación, aunque distintos y a cumplimentar de forma separada y autónoma, guardan una clara conexión. El segundo requisito [art. 89.2.b) LJCA] exige la identificación precisa de las normas o la jurisprudencia que se consideran infringidas y también que se justifique su presencia o bien que, aún en caso de ausencia, la Sala hubo de tenerlas en cuenta, siendo rechazable su cita genérica (126).

Para satisfacer el juicio de relevancia [art. 89.2.d) LJCA], no basta la cita en el escrito de preparación de las normas que se consideran infringidas por la sentencia, sino que se requiere una argumentación jurídica sobre el modo en que tales hipotéticas infracciones han sido relevantes y determinantes del fallo de la sentencia recurrida(127); haciendo explícito cómo, por qué y de qué forma la infracción de una norma estatal o comunitaria europea ha influido y ha sido determinante del fallo, si bien es suficiente que, aunque sea de forma concisa, se argumenta de forma suficiente por qué la omisión de la aplicación de las normas que identifica como infringidas ha sido el factor determinante de la desestimación de su recurso por la sentencia que pretende impugnar en casación(128).

La restricción del recurso de casación estatal a las infracciones del derecho estatal y comunitario europeo, según se ha indicado más atrás, exige la justificación de ese carácter en el caso de que la resolución recurrida haya sido dictada por las Salas territoriales [art. 89.2.e) LJCA], excluyéndose, como antes, la alegación instrumental del derecho estatal como pretexto para acceder a la casación ante elTS.

\section{Denuncia previa de las infracciones de carácter procesal}

Como se ha adelantado, la exigencia de acreditar la previa petición de subsanación si fuera posible [art. 89.2.c) LJCA] ha sido reinterpretada con arreglo a la nueva lógica casacional, exigiendo que, si la única o exclusiva razón esgrimida en casación es la incongruencia omisiva, se haya instado antes sin éxito el complemento de la sentencia por el cauce previsto en los arts. 267.5 LOPJ y 215.2 LEC.

(126) AATS de 16 de mayo de 2017 (Rec. Queja 227/2017) y de 17 de julio de 2017 (Rec. Queja 199/2017).

(127) AATS de 15 de marzo de 2017 (Rec. Queja 57/2017) y de 16 de mayo de 2017 (Rec. Queja 227/2017)

(128) AATS de 24 de abril de 2017 (Rec. Queja 61/2017) y de 29 de mayo de 2017 (Rec. Queja 205/2017). 


\section{Fundamentación del interés casacional objetivo y de la conveniencia de pronunciamiento delTS}

El sexto y último de los requisitos [art. 89.2.f) LJCA] tiene una doble dimensión: la especial fundamentación, con singular referencia al caso, se refiere a la concurrencia de alguno o algunos de los supuestos de interés casacional objetivo del art. 88.2 y 3 LJCA y también a la conveniencia de un pronunciamiento de la Sala de lo Contencioso-administrativo del TS. Este requisito tiene especial relevancia al pivotar la nueva casación sobre la noción de interés casacional objetivo para la formación de jurisprudencia, por lo que existen numerosos pronunciamientos del TS sobre su cabal cumplimiento con la precisión de exigencias específicas para determinados extremos.

\section{A) Argumentación autónOMA, ESPECífICA Y SUFICIENTE SOBRe EL INTERÉS CASACIONAL OBJETIVO}

Este requisito exige como carga procesal insoslayable del recurrente que, de forma expresa y autónoma, argumente de forma específica - por referencia singular al caso- la concurrencia de alguno o algunos de los supuestos del art. 88.2 y 3 LJCA que permiten apreciar el interés casacional objetivo y la conveniencia de un pronunciamiento del TS, por lo que no es suficiente la mera alusión o cita de alguno o algunos de tales supuestos ni una argumentación realizada de forma abstracta o desvinculada del caso concreto planteado, sino que será preciso razonar por qué el caso concreto se inscribe o subsume en el supuesto o supuestos que se aducen (129).

Por tanto, no se cumple este requisito si no se efectúa alegación alguna al respecto (130), no se menciona o invoca ninguno de tales supuestos (131), si hay una mera cita de supuestos o su alegación genérica que es insuficiente (132) o no se realiza una argumentación separada y específica de la concurrencia del interés casacional objetivo ni en términos sus-

(129) AATS de 1 de febrero de 2017 (Rec. Queja 98/2016), de 10 de mayo de 2017 (Rec. Queja 234/2017), 22 de mayo de 2017 (Rec. Queja 261/2017), de 24 de mayo de 2017 (Rec. Queja 213/2017) y de 29 de mayo de 2017 (Rec. Queja 205/2017).

(130) AATS de 1 de febrero de 2017 (Rec. Queja 98/2016) y de 15 de marzo de 2017 (Rec. Queja 57/2017).

(131) ATS de 25 de enero de 2017 (Rec. Casación 15/2016), de 1 de febrero de 2017 (Rec. Queja 111/2016), de 22 de febrero de 2017 (Rec. Queja 160/2016), 8 de marzo de 2017 (Rec. Queja 3/2017), de 15 de marzo de 2017 (Rec. Queja 57/2017), 29 de marzo de 2017 (Rec. Queja 32/2017).

(132) AATS de 24 de mayo de 2017 (Rec. Queja 213/2017) y de 29 de mayo de 2017 (Rec. Queja 205/2017). 
tantivos ni en términos formales (apartados separados) (133), que es exigible también cuando concurre una presunción del art. 88.3 LJCA(134), pues su invocación no exime de una mínima argumentación a efectos de que entre en juego la presunción y, en consecuencia, la resolución correspondiente adopte la forma jurídica de auto(135). Este requisito se diferencia netamente de la articulación de las infracciones sustantivas y procesales que se imputan a la resolución recurrida, sin que la amplia exposición de ellas comporte la satisfacción del presente requisito(136).

\section{B) EXIGENCIAS ESPECÍFICAS PARA DETERMINADOS SUPUESTOS}

Esas pautas generales se precisan o perfilan respecto de algunos supuestos mediante exigencias específicas a satisfacer para entender cumplido este requisito.

La existencia de pronunciamientos contradictorios [art. 88.2.a) LJCA] exige a la parte recurrente razonar y justificar argumentalmente la igualdad sustancial de las cuestiones examinadas en las sentencias que se someten a contraste, mediante un razonamiento que explique que, ante un problema coincidente de interpretación del ordenamiento jurídico aplicable al pleito, la sentencia impugnada ha optado por una tesis hermenéutica divergente, contradictoria e incompatible con la seguida en la sentencia de contraste, sin que sea suficiente su invocación en términos genéricos o la afirmación de que la sentencia impugnada entra en contradicción con la de contraste, sin argumentar cumplidamente tal aseveración (137).

La invocación de una doctrina gravemente dañosa para el interés general [art. 88.2.b) LJCA] exige que en el escrito de preparación: (i) se expliciten, de manera sucinta pero expresiva, las razones por las que la doctrina que contiene la sentencia discutida pueda resultar gravemente dañosa para los intereses generales, (ii) vinculando el perjuicio a tales intereses con la realidad a la que la sentencia aplica su doctrina, (iii) sin que

(133) AATS de 15 de marzo de 2017 (Rec. Queja 20/2017) y de 15 de marzo de 2017 (Rec. Queja 26/2017)

(134) ATS de 8 de marzo de 2017 (Rec. Queja 75/2017) y de 4 de julio de 2017 (Rec. Casación 1461/2017).

(135) ATS de 25 de enero de 2017 (Rec. Queja 15/2016) y de 9 de febrero de 2017 (Rec. Casación 131/2016)

(136) ATS de 5 de junio de 2017 (Rec. Queja 270/2017).

(137) AATS de 7 de febrero de 2017 (Rec. Casación 161/2016), de 29 de mayo de 2017 (Rec. Queja 205/2017), de 8 de junio de 2017 (Rec. Queja 338/2017) y de 14 de junio de 2017 (Rec. Queja 203/2017). 
baste al respecto la mera afirmación apodíctica de que el criterio de la sentencia los lesiona (138).

Respecto de la afectación a gran número de situaciones o trascendencia general [art. 88.2.c) LJCA] es preciso que el escrito de preparación (i) haga explícita esa afección, exteriorizando en un sucinto pero ineludible análisis la previsible influencia de la doctrina en otros muchos supuestos, (ii) sin que sean suficientes las meras referencias genéricas y abstractas, que presupongan sin más tal afección, (iii) ni tampoco baste la afirmación de que se produce por tratarse de la interpretación de una norma jurídica, cuya aplicación a un número indeterminado de situaciones forma parte de su naturaleza intrínseca(139).

La interpretación y aplicación del derecho comunitario en contradicción aparente con jurisprudencia del TJUE o en supuestos que puedan exigir su intervención a título prejudicial [art. 88.2.f) LJCA] precisa que la parte recurrente justifique, siquiera mínimamente, en qué consiste esa interpretación y aplicación del Derecho de la Unión Europea en contradicción con la doctrina delTribunal de Justicia (140).

La presunción de apartamiento deliberado de la jurisprudencia por considerarla errónea [art. 88.3.b) LJCA] requiere que el escrito de preparación (i) haga mención expresa a la misma, (ii) señale que la conoce y la valore jurídicamente, y (iii) se aparte de ella por entender que no es correcta; por lo que no basta una mera inaplicación de la misma por el órgano de instancia o la mera afirmación de que omite toda referencia a la jurisprudencia delTS (141).

La alegación de otras circunstancias no previstas (art. 88.2, inciso inicial, LJCA) exige a la parte recurrente que en el escrito de preparación, al menos: (i) advierta expresamente que el interés casacional objetivo no se fundamenta ni en las circunstancias del art. 88.2 LJCA ni en las presunciones del art. 88.3 LJCA, y (ii) justifique cuidada y rigurosamente el interés casacional objetivo del recurso que revela la circunstancia invocada, que lógicamente no habrá de ser reconducible a alguno de los supuestos de los apartados 2 y 3 del art. 88 LJCA(142).

Finalmente, respecto de las presunciones no absolutas [art. 88.3. a), d) y e) LJCA] es preciso acreditar que no se aprecia que el asunto carece

(138) ATS de 15 de marzo de 2017 (Rec. Casación 93/2017).

(139) AATS de 25 de enero de 2017 (Rec. Casación 15/2016), de 8 de marzo de 2017 (Rec. Casación 40/2017) y de 15 de marzo de 2017 (Rec. Casación 93/2017).

(140) ATS de 29 de mayo de 2017 (Rec. Queja 205/2017).

(141) AATS de 8 de marzo de 2017 (Rec. Casación 40/2017) y de 10 de mayo de 2017 (Rec. Casación 1150/2017).

(142) AATS de 15 de marzo de 2017 (Rec. Casación 93/2017) y de 7 de junio de 2017 (Rec. Casación 305/2017). 
manifiestamente de interés casacional objetivo para la formación de jurisprudencia (art. 88.3 in fine LJCA), lo que, en muchos casos, se resuelve mediante su alegación y consideración conjunta con el supuesto del art. 88.2.c) LJCA (143).

C) JUSTIFICACIÓN DE LA CONVENIENCIA DE PRONUNCIAMIENTO DELTS

La exigencia final del art. 89.2.f) LJCA plasma la finalidad nomofiláctica de la casación dirigida a la formación de la jurisprudencia (art. 88.1 LJCA), al imponer al recurrente la carga adicional de argumentar de forma suficiente las razones por las cuales concurre el interés casacional objetivo para la formación de jurisprudencia, sin que la mera invocación de los supuestos previstos en la norma satisfaga dicha necesidad (144).

Por tanto, es necesario fundamentar siempre en el escrito de preparación la conveniencia de que el TS se pronuncie sobre la cuestión planteada. No sólo que concurre alguno o algunos de los supuestos de los apartados 2 y 3 del art. 88 LJCA, sino también la conveniencia de un pronunciamiento de la Sala de lo Contencioso-Administrativo del TS [art. 89.2.f.) LJCA, in fine] (145).

\section{Papel de los órganos de instancia}

La reconfiguración de los órganos de instancia como colaboradores del TS mediante su reforzado papel de primer filtro al acceso a la casación, al atribuirles la inicial comprobación del cumplimiento de los requisitos por el escrito de preparación mediante auto motivado y permitirles, en caso de tener por preparado el recurso, expresar su opinión sobre el interés objetivo del recurso para la formación de jurisprudencia (art. 89.4 y 5 LJCA), suscitaba dudas sobre el alcance de ese control por los órganos de instancia (146), que han ido resolviéndose a través de los autos sobre los numerosos recursos de queja planteados denunciando un exceso en el ejercicio de esa función.

El órgano de instancia tiene la obligación de motivar la decisión de tener o no por preparado el recurso (auto motivado ex art. 89.4 y 5 LJCA),

(143) AATS de de 3 de abril de 2017 (Rec. Casación 78/2017), de 4 de abril de 2017 (Rec. Casación 331/2017) y de 26 de junio de 2017 (Rec. Casación 1829/2017).

(144) ATS de 11 de mayo de 2017 (Rec. Casación 616/2017).

(145) AATS de 15 de marzo de 2017 (Rec. Casación 93/2017) y de 5 de abril de 2017 (Rec. Casación $628 / 2017)$.

(146) RAZQUIN LIZARRAGA, "Problemas...», op. cit., págs. 63-65. 
lo que contrasta con la potestad de la Sección de Admisión de inadmitir el expresado recurso mediante providencia, a través de un razonamiento que deberá ir necesariamente referido a la verificación de si se cumplen los requisitos que el precepto impone al escrito de preparación(147). Su análisis del cumplimiento de los requisitos legales se ha de realizar de manera que se aprecien la razón o razones, relacionadas con la regulación actual del recurso de casación, que han llevado al órgano jurisdiccional a quo a tener o no tener por preparado el recurso, sin que las fórmulas apodícticas satisfagan esta exigencia (148). Se requiere una motivación mínima pero suficiente de los criterios que conducen al órgano jurisdiccional a concluir que el escrito de preparación no reúne los requisitos exigidos en el art. 89.2 LJCA(149).

Esta función del órgano de instancia es limitada: le incumbe, con carácter general, la comprobación desde una perspectiva formal de los requisitos exigidos al escrito de preparación, constituyendo función exclusiva de la Sección de Admisión pronunciarse sobre la efectiva concurrencia del interés objetivo casacional. Así, al órgano a quo le compete (art. 89.4 LJCA) el análisis formal sobre el cumplimiento de los requisitos de plazo, legitimación y recurribilidad de la resolución, así como la constatación de que en el escrito de preparación hay un esfuerzo argumentativo tendente a la justificación de la relevancia de la infracción denunciada y su carácter determinante del fallo y también, en especial, si se contiene una argumentación específica, con singular referencia al caso, de la concurrencia de alguno o algunos de los supuestos que, conforme a los apartados 2 y 3 del art. 88 LJCA, permiten apreciar el interés casacional objetivo, pero no le compete, en cambio, enjuiciar si concurre o no la infracción de fondo alegada por el recurrente, ni pronunciarse sobre la efectiva concurrencia de ese interés casacional objetivo que determina la admisión del recurso, al ser esta es una función que corresponde en exclusiva al TS (arts. 88 y 90.2 LJCA ) (150). Se trata de una verificación, prima facie, por el órgano jurisdiccional de instancia, sin perjuicio de su ulterior comprobación por elTS(151).

(147) AATS de 15 de marzo de 2017 (Rec. Queja 12/2017), de 29 de marzo de 2017 (Rec. Queja 135/2017) y de 22 de mayo de 2017 (Rec. Queja 119/2017) y de 7 de junio de 2017 (Rec. Queja 261/2017).

(148) ATS de 31 de mayo de 2017 (Rec. Queja 28/2017).

(149) ATS de 15 de febrero de 2017 (Rec. Queja 19/2017).

(150) ATS de 2 de febrero de 2017 (Rec. Queja 110/2016), cuya doctrina se reitera en muchos posteriores, entre otros, AATS de 15 de febrero de 2017 (Rec. Queja 134/2016), de 8 de marzo de 2017 (Rec. Queja 126/2016), de 22 de mayo de 2017 (Rec. Queja 261/2017), de 31 de mayo de 2017 (Rec. Queja 162/2016) y de 1 de junio de 2017 (Rec. Queja 271/2017).

(151) ATS de 8 de marzo de 2017 (Rec. Queja 41/2017). 
Así pues, al órgano de instancia le corresponde analizar si se reúnen los requisitos formales que dan acceso al recurso de casación, esto es, verificar desde una perspectiva formal si el escrito de preparación cumple los requisitos del art. 89.2 LJCA(152), pero no le compete enjuiciar si concurre o no la infracción la infracción de fondo alegada por el recurrente, ni si las infracciones imputadas han sido efectivamente relevantes y determinantes ni pronunciarse sobre la concurrencia del interés casacional objetivo que determina la admisión del recurso (153), ni enjuiciar el acierto de las afirmaciones vertidas por el recurrente, ni mucho menos valorar o pronunciarse sobre la efectiva concurrencia de ese interés objetivo casacional que determina la admisión del recurso(154), ni tampoco realizar un replanteamiento de la cuestión debatida en la instancia a efectos de la casación(155); sin perjuicio de que, si lo considera oportuno, pueda emitir el informe previsto en el art. 89.5 LJCA (156).

Esta doctrina general ha sido perfilada en algunos concretos aspectos. En primer lugar, la limitada recurribilidad de las sentencias dictadas en única instancia por los Juzgados [art. 86.1, párrafo segundo, en relación con el art. 89.2.a) LJCA] precisa que el órgano de instancia realice una específica comprobación, si bien con dispar densidad, de las dos condiciones establecidas: 1) En cuanto a la extensión de efectos, por su carácter objetivo, puede comprobar si la sentencia reúne los requisitos al efecto exigidos, sin perjuicio del posterior control que por el TS al decidir sobre la admisión (o no) del recurso; y 2) Respecto a la doctrina gravemente dañosa para los intereses generales, su actuación debe ceñirse a verificar si el escrito de preparación del recurso de casación contiene un razonamiento específico encaminado a justificar su existencia, pues la determinación de si, efectivamente, tal requisito concurre materialmente es competencia reservada a la Sección de Admisión (157). Por tanto, excede de la competencia del órgano de instancia adentrarse en la valoración de qué haya de entenderse por "doctrina que se reputa gravemente dañosa para los intereses generales», debiendo limitarse a constatar si el recurrente

(152) ATS de 29 de mayo de 2017 (Rec. Queja 205/2017).

(153) ATS de 24 de mayo de 2017 (Rec. Queja 221/2017).

(154) AATS de 8 de febrero de 2017 (Rec. Queja 113/2017) y de 22 de febrero de 2017 (Rec. Queja 7/2017).

(155) ATS de 22 de marzo de 2017 (Rec. Queja 18/2017)

(156) ATS de 22 de marzo de 2017 (Rec. Queja 55/2017).

(157) AATS de 27 de febrero de 2017 (Rec. Queja 36/2017), de 15 de marzo de 2017 (Rec. Queja 35/2017), de 5 de abril de 2017 (Rec. Queja 42/2017); de 30 de mayo de 2017 (Rec. Queja 265/2017) y de 10 de julio de 2017 (Rec. Queja 112/2017) 
ofrece una justificación suficiente a efectos de tener por preparado el recurso, con independencia de si la comparte o no (158).

En segundo lugar, respecto de la limitación del alcance del recurso a las cuestiones de derecho con exclusión de las de hecho (art. 87 bis. 1 LJCA), el órgano de instancia únicamente puede tener por no preparado el recurso si se aprecia con claridad que el escrito de preparación se limita a plantear la mera discrepancia de la parte recurrente con la apreciación de los hechos efectuada por la resolución recurrida (valoración de la prueba)(159), pero si este obstáculo no resulta con evidencia de su lectura (como puede ocurrir, v. gr., cuando en él no se discuten tanto los hechos como las consecuencias jurídicas anudadas a ellos) lo procedente es tener el recurso por bien preparado (siempre, por supuesto, que se cumplan los demás requisitos) (160).

En tercer lugar, en cuanto a la referencia del recurso de casación ante el TS al Derecho estatal y comunitario europeo, el órgano de instancia puede verificar desde el punto de vista formal la recurribilidad de la sentencia, descartándola ante la invocación de derecho autonómico (161), pero no le compete declarar si la invocación de la normativa estatal que se considera infringida lo es de una forma instrumental, versando el recurso sobre derecho autonómico, cuando este último aspecto no es evidente ni se desprende del propio escrito de preparación del recurso (162).

En cuarto lugar, respecto de la especial fundamentación del interés casacional objetivo [art. 89.2.f) LJCA], corresponde al órgano de instancia un control formal y no material dirigido a verificar si se realiza la argumentación o justificación exigida. La Sala de instancia puede apreciar la ausencia de esta exigencia cuando en el escrito de preparación se limita a citar una supuesta contradicción entre dos sentencias sin justificar la existencia de una doctrina contradictoria en las sentencias enfrentadas (163) o si la parte recurrente se limita a afirmar, para justificar el interés casacional, que la doctrina sentada puede afectar a un gran número de casos similares, sin incluir cualquier otra consideración que avale esta afirma-

(158) ATS de 28 de febrero de 2017 (Rec. Queja 40/2017) y de 5 de abril de 2017 (Rec. Queja 42/2017).

(159) ATS de 8 de marzo de 2017 (Rec. Queja 8/2017).

(160) ATS de 29 de mayo de 2017 (Rec. Queja 230/2017).

(161) AATS de 19 de abril de 2017 (Rec. Queja 170/2017) y de 26 de junio de 2017 (Rec. Queja 295/2017).

(162) ATS de 15 de marzo de 2017 (Rec. Queja 51/2017).

(163) AATS de 8 de marzo de 2017 (Rec. Queja 126/2017), de 15 de marzo de 2017 (Rec. Queja 15/2017), de 29 de mayo de 2017 (Rec. Queja 205/2017), y de 31 de mayo de 2017 (Rec. Queja 162/2016). 
ción(164). En cambio, no puede pronunciarse sobre si, materialmente, concurre el interés casacional o sobre si la sentencia fija una interpretación de las normas sobre las que se fundamente el fallo contradictoria con otros órganos jurisdiccionales o si sienta una doctrina gravemente dañosa para los intereses generales(165).

Finalmente, a la vista los autos de admisión e inadmisión, parece que los órganos de instancia han utilizado poco la posibilidad de emitir informe sobre la concurrencia del interés casacional objetivo (art. 89.5 LJCA), con el siguiente resultado: existen informes tanto negativos como favorables; la Sección de Admisión normalmente se limita a constatar tal circunstancia en los antecedentes sin referencia posterior(166), con algunas salvedades en que se menciona para estimar la concurrencia de dicho interés (167); el sentido favorable del informe no asegura la admisión del recurso que puede ser inadmitido(168); y, pese al informe desfavorable, el recurso es admitido(169).

\section{Admisión del recurso}

\section{Objeto y estructura de las decisiones}

El trámite de admisión tiene por objeto principalmente -amén de verificar si se cumplen los requisitos para acceder a la casación - decidir si existe interés casacional objetivo en el recurso, ya que solo podrá admitirse a trámite el recurso cuando el examen de las infracciones presente tal interés(170), lo que corresponde en exclusiva a la Sección Primera o de Admisión, sin que puedan pronunciarse sobre ella los órganos de instancia (171).

Los autos de admisión se estructuran en tres partes: antecedentes de hecho, razonamientos jurídicos y acuerdo o decisión. Su fundamentación jurídica - aunque no uniforme y con extensión dispar - constata de

(164) ATS de 8 de marzo de 2017 (Rec. Queja 126/2016).

(165) ATS de 30 de mayo de 2017 (Rec. Queja 4/2017).

(166) AATS de de 27 de enero de 2017 (Rec. Casación 1/2016) y de 16 de mayo de 2017 (Rec. Casación 922/2017).

(167) AATS de 18 de junio de 2017 (Rec. Casación 1476/2017) y de 17 de julio de 2017 (Rec. Casación 2160/2017).

(168) AATS de 8 de marzo de 2017 (Rec. Casación 242/2016) y de 21 de junio de 2017 (Rec. Casación 1983/2017).

(169) ATS de 22 de mayo de 2017 (Rec. Casación 1306/2017).

(170) ATS de 21 de marzo de 2017 (Rec. Casación 308/2016).

(171) Por todos, ATS de 2 de febrero de 2017 (Rec. Queja 110/2016). 
forma breve -e incluso apodíctica - el cumplimiento de los requisitos (172) y a continuación pondera la concurrencia del interés casacional objetivo normalmente mediante un doble y sucesivo razonamiento: concreción de la cuestión jurídica planteada y subsiguiente ponderación de si respecto de ella concurre el interés casacional objetivo, tras lo que se identifica la cuestión objeto del recurso(173). Ello tiene continuidad en el acuerdo (art. 90.4 LJCA) que, también sin uniformidad en apartados, expresa la admisión del recurso de casación, la identificación de la cuestión que presenta interés casacional objetivo para la formación de la jurisprudencia y de la norma que va a ser objeto de interpretación, así como la publicación del auto en la página web delTS, la comunicación inmediata al órgano de instancia y la remisión de las actuaciones a la Sección competente de la Sala (174).

La interdependencia entre cuestión jurídica e interés casacional objetivo conlleva que el planteamiento de varias cuestiones o infracciones vaya seguido del análisis separado de cada una de ellas para determinar si concurre el interés casacional objetivo(175); y la admisión puede referirse a una o varias de las cuestiones o infracciones jurídicas alegadas, con rechazo de las restantes (176). Por otra parte, la inadmisión por providencia de recursos de casación sobre solicitudes similares no impide la posterior admisión de otro recurso que plantea cuestiones son suscitadas en aquéllos (177).

Para admitir el recurso basta la concurrencia de uno de los supuestos que permiten apreciar la existencia de interés casacional objetivo (178). La Sección de Admisión puede examinar bien todos los supuestos alegados por el recurrente y apreciar la concurrencia de todos(179) o varios de ellos(180), o bien seleccionar y ponderar uno o

(172) Así, AATS de 17 de mayo de 2017 (Rec. Casación 129/2017) y de 21 de julio de 2017 (Rec. Casación 2020/2017). En su caso, se examinan las alegaciones de la parte recurrida en contra de la admisión del recurso (ATS de 6 de julio de 2017, Rec. Casación 1961/2017).

(173) Entre otros, ATS de 17 de mayo de 2017 (Rec. Casación 255/2016).

(174) Por todos, ATS 1 de febrero de 2017 (Rec. Casación 36/2016).

(175) AATS de 5 de mayo de 2017 (Rec. Casación 1380/2017) y de 31 de mayo de 2017 (Rec. Casación 1246/2017).

(176) Así, AATS de 27 de febrero de 2017 (Rec. Casación 151/2016), de 15 de marzo de 2017 (Rec. Casación 212/2017) y 22 de marzo de 2017 (Rec. Casación 122/2016).

(177) ATS de 21 de julio de 2017 (Rec. Casación 2586/2017).

(178) ATS de 5 de abril de 2017 (Rec. Casación 196/2017).

(179) ATS de 18 de enero de 2017 (Rec. Casación 13/2016).

(180) Por todos, AATS de 1 de marzo de 2017 (Rec. Casación 128/2016), de 15 de marzo de 2017 (Rec. Casación 212/2017), de 3 de abril de 2017 (Rec. Casación 480/2017), de 24 de mayo de 2017 (Rec. Casación 38/2017) y de 5 de julio de 2017 (Rec. Casación 2154/2017). 
varios de ellos que estima más pertinentes, dejando sin analizar los restantes por ser innecesario (181).

Ahora bien, todo ello no impide que, en ocasiones, también los autos de admisión estimen la existencia del interés casacional objetivo de forma breve e incluso apodíctica(182).

\section{Procedimiento y forma de las resoluciones}

La parte recurrida, con frecuencia, suele oponerse en su escrito de comparecencia ante el TS a la admisión del recurso (art. 89.6 LJCA). Y el TS no ha utilizado el excepcional trámite de audiencia (art. 90.1 LJCA) ni tan siquiera en caso de informe desfavorable del órgano de instancia o de oposición a la admisión por la parte recurrida.

La admisión del recurso de casación se adopta siempre mediante auto motivado [arts. 90.3.a) y 90.4 LJCA]. Y la inadmisión se acuerda mediante providencia, salvo que el órgano de instancia hubiese emitido opinión favorable o se alegue uno de los supuestos del art. 88.3 LJCA en que se exige la forma de auto motivado [art. 90.3.a) y b) LJCA] (183). Sin embargo, no resulta exigible la forma de auto en caso de alegación de una presunción - art. 88.3.a) LJCA-, si el escrito de preparación del recurso no ofrece fundamentación suficiente que integre con un mínimo de solidez el presupuesto para desencadenar la presunción (184).

La mayoría de las inadmisiones se acuerdan mediante providencia que se limita a indicar, de forma muy escueta o apodíctica, la concurren-

\footnotetext{
(181) En numerosos casos se indica que la concurrencia de uno de los supuestos hace innecesario examinar si concurren los otros alegados [por todos, AATS 27 de febrero de 2017 (Rec. Casación 151/2016), de 22 de marzo de 2017 (Rec. Casación 261/2017), de 21 de junio de 2017 (Rec. Casación 1193/2017) y de 6 de julio de 2017 (Rec. Casación 1187/2017). Y en otros sin esa indicación [AATS de 20 de febrero de 2017 (Rec. Casación 139/2017), de 13 de marzo de 2017 (Rec. Casación 6/2017); de 10 de mayo de 2017 (Rec. Casación 914/2017) y de 21 de junio de 2017 (Rec. Casación 1101/2017).
}

(182) Así el ATS de 29 de marzo de 2017 (Rec. Casación 1063/2017), tras concretar la cuestión jurídica planteada, dice: "Así formulada, la cuestión revise interés casacional objetivo para la formación de jurisprudencia, pues exige un pronunciamiento sobre un problema jurídico que trasciende del caso objeto del pleito"; el ATS de 22 de mayo de 2017 (Rec. Casación 880/2017) dice solo "coincidiendo con el recurrente»; el ATS de 30 de mayo de 2017 (Rec. Casación 785/2017) se remite a los argumentos del recurrente ya expuestos en los antecedentes; y para el ATS de 4 de julio de 2017 (Rec. Casación 1561/2017) los argumentos que expone el recurrente llevan a la Sección de Admisión a entender que, en efecto, presenta interés casacional objetivo para la formación de jurisprudencia la cuestión siguiente.

(183) Por ello, la inadmisión por providencia en los supuestos del art. 88.2 LJCA resulta excepcionada cuando son alegados conjuntamente con las presunciones del apartado 3 del mismo precepto. Por todos, ATS de 8 de marzo de 2017 (Rec. Casación 40/2017).

(184) ATS de 30 de marzo de 2017 (Rec. Casación 266/2016). 
cia de una de las circunstancias de inadmisión (art. 90.4 LJCA) (185). Sin embargo, la providencia de inadmisión no puede considerarse como una resolución carente de motivación, ni esa forma puede ser tachada de anómala, ni de generadora de indefensión (186).

Los autos de admisión se publican en la web del TS (art. 90.7 LJCA), pero no los autos de inadmisión (si bien son accesibles por otras vías). En cambio, no existe publicidad de las providencias de inadmisión, pese a representar, con mucho, el mayor número de resoluciones.

\section{Recursos admitidos}

El número de recursos admitidos en el primer año asciende a 511 (253 remitidos a la sección segunda; 64 a la tercera; 136 a la cuarta y 58 a la quinta). Según la información general ofrecida por la Web delTS, a fecha 31 de mayo de 2017, se habían presentado 2.976 recursos de casación de la LO 7/2015, de los cuales habían obtenido una resolución sobre su admisión o inadmisión 1.432 recursos, con el resultado de 245 admitidos (17,11\%), 980 inadmitidos (912 por providencia y 68 por auto) y 207 por otras causas (187).

(185) Así la Providencia de 15 de junio de 2017 (Rec. Casación 2030/2017) acuerda la inadmisión en aplicación de lo dispuesto en el art. 90.4.d) LJCA «y ello por cuanto el recurso que se prepara carece de interés casacional objetivo para la formación de jurisprudencia»; y las Providencias de 22 de junio de 2017 (Recs. Casación 1714/2017 y 1768/2017) se justifican en el incumplimiento de las exigencias que el art. 89.2 LJCA impone al escrito de preparación, por falta de fundamentación suficiente de que concurran alguno o algunos de los supuestos que, con arreglo a los apartados 2 y 3 del art. 88, permiten apreciar el interés casacional objetivo y la conveniencia de un pronunciamiento delTS, por no justificarse la concurrencia del presupuesto establecido para que resulte operativa la presunción del art. 88.3.a) conforme al art. 90.4.b) en relación con el art. 89.2.f), así como por la carencia de interés casacional objetivo para la formación de jurisprudencia conforme al art. 90.4.d) en relación con el art. 89.2.f) LJCA. Nótese que propia Sala Tercera del TS, «Problemas interpretativos de la nueva regulación contencioso-administrativa», pág. 21 , señaló que las providencias de inadmisión requieren una minima motivación y, además, «deberían incorporar una breve explicación de la razón por la que se aprecia que no concurre la circunstancia que se indica, pues hacerlo así no dificultará en exceso la labor de aquella Sección y acallará en gran medida la sensación o queja de arbitrariedad".

(186) ATS de 30 de marzo de 2017 (Rec. Casación 266/2016). En este sentido, VELASCO CABALLERO, op. cit., § 51, entiende que las providencias de inadmisión satisfacen en abstracto las exigencias del motivación del art. $24 \mathrm{CE}$.

(187) Tales datos y ese porcentaje deben ser matizados por dos motivos: de un lado, tal porcentaje se refiere a los recursos vistos por la Sección de Admisión, esto es, los elevados alTS sin incluir los no tenidos por preparados por los órganos inferiores, que en muchos casos han dado lugar a recursos de queja. Y, de otro, un elevado número de recursos admitidos son repetitivos al referirse a la misma norma y cuestión. En los remitidos a la Sección Segunda aproximadamente un $50 \%$ son repetidos: así, 67 asuntos se refieren al IRPF por becas de estudios en el extranjero y 43 al impuesto de transmisiones patrimoniales y actos jurídicos documentados (modalidad de transmisiones patrimoniales onerosas) con ocasión de la transmisión de metales preciosos por un particular a un empresario o profesional del sector; en los enviados a la Sección Tercera, 21 asuntos se 
En cuanto al interés casacional objetivo, los supuestos más alegados y estimados por la Sección de Admisión para admitir el recurso son las circunstancias del art. 88.2.a) (doctrina contradictoria) y del art. 88.2.c) LJCA (afectación a gran número de situaciones o transcendencia general del asunto) y la presunción del art. 88.3.a) (inexistencia de jurisprudencia).

La mayoría de los recursos admitidos corresponde a cuestiones en materia fiscal o tributos (Sección Segunda) y de Seguridad Social (Sección Cuarta), así como se abordan cuestiones relevantes referidas a los sectores regulados - sobre todo, transporte por carretera- (Sección Tercera) (188). En cambio, es muy reducido el número de asuntos admitidos en materia de responsabilidad patrimonial(189) - sin que se aprecie ninguno de responsabilidad patrimonial sanitaria - por tener normalmente un carácter casuístico $\mathrm{y}$, sobre todo, han minorado notablemente los recursos admitidos en materia de expropiación forzosa que se refieren ahora a aspectos jurídicos muy concretos (190)

\section{Costas}

La inadmisión del recurso conlleva la condena en costas, que puede limitarse a una parte o a una cantidad máxima (art. 90.8 LJCA). Se aplican con carácter general las cuantías siguientes: 1.000 euros si no ha existido oposición a la admisión por la parte recurrida y 2.000 euros cuando se ha formulado tal oposición(191).

refieren a las restricciones aplicables al arrendamiento de vehículos con conductor tras la entrada en vigor de la Ley 9/2013; en los remitidos a la Sección Cuarta, 19 asuntos versan sobre la calificación del cese de los trabajadores en un ERE cuando dicho cese se acuerda individualmente con el empresario; y en los enviados a la Sección Quinta, 12 recursos contemplan la interpretación del art. 108.3 LJCA.

(188) PALOMAR OLMEDA, Alberto, "Los Autos de admisión en algunos de los sectores regulados más significativos", Diario La Ley, N. ${ }^{\circ}$ 9013, de 4 de julio de 2017.

(189) AATS de 28 de abril de 2017 (Rec. Casación 839/2017), de 5 de junio de 2017 (Rec. Casación 1750/2017), de 12 de junio de 2017 (Rec. Casación 1548/2017) y de 17 de julio de 2017 (Rec. Casación 1847/2017). En el año anterior a la entrada en vigor del nuevo sistema, la Sala Tercera del TS dictó 113 sentencias en materia de responsabilidad patrimonial de la Administración (11 de ellas en el ámbito sanitario).

(190) AATS de 20 de febrero de 2017 (Rec. Casación 210/2016), de 24 de abril de 2017 (Rec. Casación 313/2017), de 16 de mayo de 2017 (Rec. 755/2017), de 16 de mayo de 2017 (Rec. 1182/2017) y de 12 de junio de 2017 (Rec. Casación 1478/2017). En el año anterior a la entrada en vigor del nuevo sistema, la Sala Tercera delTS dictó 247 sentencias en materia de expropiación forzosa.

(191) AATS de 12 de junio de 2017 (Rec. Casación115/2017), de 14 de junio de 2017 (Rec. Casación 665/2017) y de 21 de junio de 2017 (Rec. Casación 1983/2017). Igual criterio se sigue en las providencias de inadmisión. 


\section{El carácter jurisprudencial de la sentencia final}

En el primer año el TS ha dictado, previa celebración de vista pública (art. 92.6 LJCA), dos sentencias finales resolviendo recursos de casación interpuestos con arreglo al nuevo sistema(192). Ello supone una mayor celeridad en la resolución del recurso (entre nueve y trece meses desde la fecha de la sentencia recurrida).

En este momento convergen las funciones de la casación, objetiva (ius constitutionis) y subjetiva (ius litigatoris). Las sentencias finales pretenden satisfacer la doble función encomendada en el art. 93 LJCA, según se refleja en su fundamentación jurídica que, primero, se centra en la interpretación jurídica de las normas relativas a tales cuestiones admitidas fijando el criterio de la Sala sobre ellas y determina explícitamente esa interpretación o respuesta a las cuestiones que presentan interés casacional objetivo; y, luego, resuelve, de acuerdo con esa interpretación, el caso estimando o desestimando el recurso contencioso-administrativo mediante un breve razonamiento, lo que se proyecta en el fallo que declara haber o no haber lugar al recurso de casación anulando o confirmando la sentencia recurrida, estima o desestima el recurso contencioso-administrativo y se pronuncia sobre las costas.

La sentencia final tiene, por tanto, un carácter más jurisprudencial a fin de plasmar su primordial finalidad nomofiláctica para la formación de jurisprudencia(193), separándose netamente del esquema anterior basado en motivos (194). La fundamentación jurídica se dirige a determinar la interpretación de las normas y la respuesta a las cuestiones identificadas en el auto de admisión, fijando de forma explícita la "ratio decidendi» que constituye jurisprudencia y podrá invocarse en ulteriores procesos y recursos (195).

(192) SSTS (Sección 3. a) 1199/2017, de 7 de julio (Rec. Casación 161/2016) y (Sección 5. ) 1295/2017, de 18 de julio (Rec. Casación 298/2016). Al cierre de este trabajo (25 de octubre de 2017) se han publicado en la Web del TS otras cinco sentencias: SSTS (Sección 3. ${ }^{a}$ ) 1352/2017, de 24 de julio (Rec.

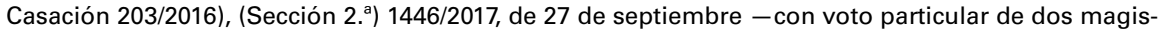
trados - (Rec. Casación 194/2016), (Sección 3.a) 1517/2017, de 5 de octubre (Rec. Casación 139/2016), (Sección 3. a) 1547/2017, de 16 de octubre (Rec. Casación 75/2017) y (Sección 3. a) 1548/2017, de 16 de octubre (Rec. Casación 565/2017).

(193) SANTAMARÍA PASTOR, op. cit., pág. 41; y RAZQUIN LIZARRAGA, "Problemas...., cit., págs. 68-69.

(194) Por todas, STS (Sección 5. a) 1339/2017, de 19 de julio (Rec. Casación 2868/2016), que, pese a la coincidencia temporal, resuelve un recurso de casación interpuesto conforme a la anterior regulación.

(195) Así lo había reclamado la doctrina. Por todos, MUÑOZ MACHADO, Santiago, Tratado de Derecho Administrativo y Derecho Público General. El ordenamiento jurídico, lustel, Madrid, t. II, 1 . $^{\text {a ed., }}$ 2006, págs. 127-131. 
Sin embargo, las sentencias finales no siguen un modelo uniforme ni se articulan en apartados o parágrafos ni existe un criterio unánime sobre la inserción de la interpretación de las normas previamente fijada en el fallo(196).

\section{Los problemas del recurso de casación autonómico}

Frente al sistema anterior que contemplaba dos específicos recursos de casación autonómicos (197), la reforma solo prevé un recurso de casación fundado en infracciones del Derecho autonómico atribuyendo su conocimiento a una sección especial de la Sala de lo Contencioso-administrativo del Tribunal Superior de Justicia (art. 86.3, párrafos segundo y tercero, LJCA). Una modalidad especial plagada de problemas y cuestiones por su insuficiente regulación y las dificultades para trasladar aquí el régimen general referido al recurso de casación estatal ante el TS, lo que imponía una nueva modificación legal que la regulase(198). Esta problemática se refleja en la actuación de las Salas territoriales. Una de ellas considera que no existe el recurso de casación autonómico (199) y la mayoría admite su existencia pero, partiendo de la aplicación analógica de la regulación de la casación estatal, ha adoptado criterios dispares sobre aspectos relevantes (200).

En cuanto al objeto, la posición mayoritaria entiende que son recurribles las sentencias de los Juzgados y también las sentencias y autos de las propias Salas en los mismos supuestos y con los mismos requisitos establecidos para el recurso de casación estatal (arts. 86 y 87 LJCA), aunque ceñido obviamente a los casos en que el recurso se funde en infrac-

(196) De las siete SSTS citadas, solo dos de ellas (SSTS 1352/2017, de 24 de julio, y 1446/2017, de 27 de septiembre) llevan la interpretación normativa al fallo.

(197) Recurso de casación por unificación de doctrina autonómica frente a las sentencias de las Salas de lo Contencioso-Administrativo de los Tribunales Superiores de Justicia (antiguo art. 99 LJCA) y recurso en interés ley autonómico contra sentencias dictadas en única instancia por los Juzgados de lo Contencioso-Administrativo (antiguo art. 101 LJCA). Recursos que, pese a su derogación en la reforma de la LJCA por la Ley Orgánica 7/2015, continúan presentes en los 74.5 y 6 LOPJ y 10.5 y 6 LJCA (no modificados).

(198) RAZOUIN LIZARRAGA, «Problemas...», op. cit., págs. 57-58. La propia Sala Tercera, «Problemas interpretativos de la nueva regulación contencioso-administrativa" (octubre 2015), pág. 6, reconoció que muchas previsiones de la nueva regulación eran inadecuadas y en muchos casos inviables para esta modalidad y propuso una concreta modificación legal mediante una nueva Sección 4. ${ }^{\text {a }}$, titulada «Recursos de casación autonómicos» (art. 97 y ss).

(199) La Sala del TSJ de Extremadura ha informado a la Sala de Gobierno que considera que no existe el recurso de casación autonómico y que en cualquier caso no es posible frente a sentencias de la propia Sala.

(200) En la sección correspondiente a losTSJ de la Web del CGPJ, sólo en dos casos (Asturias y Navarra) existe un apartado específico para la publicidad de los autos de admisión. Hasta mediados de octubre de 2017, sólo aparecen publicados 3 autos de admisión de la Sala del Principiado de Asturias. 
ción de normas autonómicas(201). En cambio, otra tesis sostiene que el recurso de casación autonómico está limitado a las sentencias dictadas en única instancia por los Juzgados, quedando fuera las sentencias de la propia Sala en razón de que la posición constitucional de los TSJ como órgano que culmina la organización judicial en el territorio de la Comunidad Autónoma es análoga al del TS en materia de derecho estatal y la contradicción de su admisión con el diseño de la nueva casación (202).

En relación con el interés casacional objetivo, algunas Salas territoriales toman en consideración los supuestos de los apartados 2 y 3 del art. 88 LJCA (203), si bien matizando que la «jurisprudencia» es en este caso la del TSJ y no la delTS(204) ni la de otros TSJ (205). Pero otras Salas restringen el interés casacional objetivo para la formación de jurisprudencia en los recursos frente a sentencias de las Salas de lo Contencioso-Administrativo de los Tribunales Superiores de Justicia, a salvo de la existencia de supuestos no expresamente previstos en el art. 88 LJCA y del juicio que merezca en cada caso el supuesto de presunción de interés casacional del art. 88.3.c) LJCA, a dos casos: uno, cuando exista doctrina contradictoria, en interpretación de normas de Derecho autonómico, con la establecida en otra u otras sentencias de la misma Sala sobre cuestiones sustancialmente iguales [art. 88.2.a) LJCA], salvo que ello se deba a un legítimo y razonado cambio de criterio de la misma Sección o Tribunal; $y$, otro, si la resolución recurrida se apartara deliberadamente de la "jurisprudencia» sobre Derecho autonómico existente hasta entonces [art. 88.2.b) LJCA] con la única salve-

(201) Auto de la Sección de Casación de la Sala de lo Contencioso-Administrativo delTSJ de Madrid de 17 de mayo de 2017 (Rec. Casación 10/2017); cuyo criterio siguen los Autos de 23 de junio de 2017 (Rec. Casación 28/2017 y 33/2017) de la Sección Especial de Casación de la Sala de lo Contencioso-Administrativo del TSJ de Castilla y León con sede en Burgos, y de la Sección Especial de Casación Autonómica de de la Sala de lo Contencioso-Administrativo delTSJ de Navarra de 15 de junio de 2017 (Rec. 566/2016). Por su parte, los Autos de la Sección de Casación de la Sala de lo Contencioso-Administrativo delTSJ del País Vasco de 24 de febrero de 2017 (Rec. Casación 1/2017 y 2/2017) y de 10 de mayo de 2017 (Rec. Casación 4/2017) no plantean cuestión sobre la recurribilidad de sentencias en única instancia o en apelación de la propia Sala; y los Autos de la Sección de Casación de la Sala de lo Contencioso-Administrativo del TSJ de Asturias de 25 de abril de 2017 (Rec. Casación 2/2016) y de 17 de mayo de 2017 (Rec. Casación 2/2017) admiten los recursos de casación planteados contras sentencias en única instancia y en apelación dictadas por dicha Sala.

(202) Auto de la Sección de Casación de la Sala de lo Contencioso-Administrativo del TSJ de Cataluña de 10 de mayo de 2017 (Rec. Casación 3/2017). En este sentido, SOSPEDRA NAVAS, Francisco Javier, «El controvertido ámbito de las resoluciones recurribles en el recurso de casación contencioso-administrativo" en Revista Aranzadi Doctrinal, núm. 3, 2017, págs. 31-50.

(203) Autos de la Sección de Admisión de la Sala de lo Contencioso-Administrativo delTSJ de Asturias de 25 de abril de 2017 (Rec. Casación 2/2016) y de 17 de mayo de 2017 (Rec. Casación 2/2017) y de la Sala de lo Contencioso-Administrativo delTSJ de Galicia (Coruña) de 5 de mayo de 2017 (Rec. Queja 54/2017).

(204) Autos de la Sección de Casación de la Sala de lo Contencioso-Administrativo del TSJ del País Vasco de 24 de febrero de 2017 (Rec. Casación 1/2017 y 2/2017).

(205) Auto de la Sección Especial de Casación Autonómica de de la Sala de lo Contencioso-Administrativo delTSJ de Navarra de 15 de junio de 2017 (Rec. 566/2016). 
dad de que el apartamiento lo fuera respecto del criterio sostenido con anterioridad por la misma Sección, quedando, además, fuera de la casación autonómica la separación de la jurisprudencia delTS(206).

En todo caso, el acceso a la casación exige el cumplimiento de los requisitos establecidos para el escrito de preparación (art. 89.2 LJCA) (207), como es el juicio de relevancia (208). Y asimismo esta especialidad se ciñe a las cuestiones jurídicas con exclusión de las de hecho (art. 87bis.1 LJCA) y, por tanto, las referidas a la valoración de la prueba (209).

En último término, las primeras sentencias finales de las Salas territoriales no siguen la línea de las dictadas por el TS, sino que conservan un carácter más judicial - resolución del concreto asunto - sin llegar a fijar la concreta interpretación de la norma o cuestión identificada en el auto de admisión (210).

\section{Conclusión}

EITS, a través de las numerosas resoluciones dictadas en este primer año, ha ido completando el régimen del recurso de casación estatal mediante la fijación de pautas interpretativas de la nueva regulación que pretender aportar precisión y reducir la incertidumbre legislativa (211).

La jurisprudencia ha concretado el concepto jurídico indeterminado de interés casacional objetivo para la formación de jurisprudencia, que es la piedra angular sobre la que pivota el nuevo sistema casacional, perfilando los supuestos legales - circunstancias y presunciones-que permiten apreciar su concurrencia mediante una interpretación estricta. La ponderación de la existencia de tal interés no es una operación de subsunción

(206) Auto de la Sección de Casación de la Sala de lo Contencioso-Administrativo del TSJ de Madrid de 17 de mayo de 2017 (Rec. Casación 10/2017); cuyo criterio siguen los Autos de 23 de junio de 2017 (Rec. Casación 28/2017 y 33/2017) de la Sección Especial de Casación de la Sala de lo Contencioso-Administrativo del TSJ de Castilla y León con sede en Burgos, y el Auto 18/2018, de 2 de marzo (Rec. Casación 5/2018), de la Sala de lo Contencioso-Administrativo del Tribunal Superior de Justicia del País Vasco.

(207) Auto de la Sección de Admisión de la Sala de lo Contencioso-Administrativo del TSJ de Asturias de 11 de abril de 2017 (Rec. Casación 1/2016).

(208) Autos de la Sección de Casación de la Sala de lo Contencioso-Administrativo del TSJ del País Vasco de 10 de mayo de 2017 (Rec. Casación 4/2017) y de la Sala de lo Contencioso-Administrativo delTSJ de Asturias de 15 de mayo de 2017 (Rec. Queja 1/2017)

(209) Auto de la Sala de lo Contencioso-Administrativo delTSJ de Galicia (Coruña) de 17 de marzo de 2017 (Rec. Queja 36/2017).

(210) Sentencia de la Sala de lo Contencioso-Administrativo del TSJ de Galicia (Coruña) núm. 391/2017, de 21 de septiembre (Rec. Casación 4547/2016); y Sentencia de la Sala de lo Contencioso-Administrativo delTSJ de Asturias 780/2017, de 3 de octubre (Rec. Casación 2/2016).

(211) Como apunta VELASCO CABALLERO, op. cit., §§ 25, con referencia al amparo constitucional, a la vista de la STEDH de 20 de enero de 2015 (caso Arribas Antón). 
en razón del espacio interpretativo abierto de los supuestos legales y, a la postre, del criterio de oportunidad presente en la conveniencia de pronunciamiento para la formación de jurisprudencia (212). La existencia del interés casacional objetivo -y con ello, la admisión del recurso- depende de la estimación exclusiva y discrecional de la Sección de Admisión -en muchos casos, escueta o apodíctica-, que goza de un amplio margen de apreciación para seleccionar los asuntos que estima convenientes para la formación de jurisprudencia y definir su propia tarea (213).

Las exigencias formales han sido notablemente reforzadas. El escrito de preparación tiene un papel esencial debiendo cumplir de forma justificada y suficiente los requisitos exigidos y. en particular, el último de ellos mediante una argumentación específica, singular y adecuada sobre la concurrencia de alguno de los supuestos de interés casacional objetivo y la conveniencia de pronunciamiento delTS. Asimismo, se conservan condiciones precedentes pero con mayor rigor: la absoluta improcedencia de suscitar cuestiones nuevas, la reafirmación restrictiva de la excepcionalidad de plantear cuestiones relativas a la valoración de la prueba y la exclusión en la práctica de las infracciones procedimentales (incongruencia omisiva) por la exigencia de instar un remedio previo o por su accesoriedad respecto de la cuestión sustantiva planteada.

El ámbito cuasi universal del recurso es un espejismo por la criba en los filtros de acceso a la casación. El número de recursos admitidos es bajo (17,11 \% sobre los vistos por la Sección de Admisión) y entraña una drástica reducción respecto de la regulación anterior $(-87 \%)(214)$, especialmente notable en determinadas materias cuantitativamente relevantes (expropiación forzosa). E incluso no se ha producido un desbordamiento del número de recursos de casación preparados - como había pronosticado la doctrina (215) - ante la dificultad de cumplir el requisito del art. 89.2.f) LJCA y por el efecto disuasorio de la condena en costas en caso de inadmisión.

Ese diseño de la nueva casación parece seguir al régimen del amparo constitucional, tomado como referencia en la reforma (216). La admisión se configura hacia un modelo de discrecionalidad con algunos elementos

(212) HUELÍN MARTÍNEZ DE VELASCO, op. cit.,

(213) Como había anticipado de forma unánime la doctrina. Por todos, RAZQUIN LIZARRAGA, «EI nuevo...", op. cit., pág. 169.

(214) Según la Base de datos de la estadística judicial (PC-AXIS) del CGPJ, el total de recursos de casación ingresados en la SalaTercera delTS fue de 3.990 en 2015 y de 4.007 en 2014.

(215) SANTAMARÍA PASTOR, op. cit., págs. 38-40; y QUINTANA CARRETERO y otros, op. cit., págs. 25 y 34.

(216) RAZQUIN LIZARRAGA, «EI nuevo...», op. cit., pág. 158; FERNÁNDEZ FARRERES, op. cit., pág. 127; y VELASCO CABALLERO, op. cit., §§ 21-30. 
reglados (217). Existe incertidumbre sobre la viabilidad del recurso de casación para los recurrentes por no ser predecible su admisión; y, en cambio, hay certeza sobre su inviabilidad(218). Ahora bien, el TS reitera que no existe infracción del derecho fundamental a la tutela judicial efectiva en cuanto al acceso a los recursos por ser un derecho de configuración legal (219).

La sentencia final se dicta con mayor celeridad (en torno a un año) y explicita la concreta doctrina o interpretación de la cuestión o norma fijada por elTS, lo que, unido a la publicidad de los autos de admisión, permite a los operadores jurídicos conocer las cuestiones jurídicas a debate y la jurisprudencia establecida.

Por otra parte, la implantación del recurso de casación autonómico, más bien escasa, ha generado problemas y disparidades en las Salas territoriales, considerándose necesaria y urgente su completa y adecuada regulación.

En suma, la doctrina jurisprudencial del TS ha aportado pautas sobre la nueva regulación, ceñidas especialmente a la interpretación de la noción de interés casacional objetivo, que ayudan a su entendimiento y aplicación por los operadores jurídicos. Pero es prematuro afirmar que el nuevo recurso de casación contencioso-administrativo cumpla plenamente la finalidad de intensificar las garantías en la protección de los derechos de los ciudadanos (220), ante la drástica restricción de la admisión (en términos generales y en determinadas materias) y sus efectos colaterales sobre los remedios relativos a las infracciones de carácter procesal, a falta todavía de conocer el impacto real del nuevo sistema sobre la litigiosidad en los niveles inferiores.

Trabajo recibido el 26 de octubre de 2017

Aceptado por el Consejo de Redacción el 16 de febrero de 2018

(217) VELASCO CABALLERO, op. cit., §§ 25-26 y 38.

(218) Como advirtieron FERNÁNDEZ FARRERES, op. cit., pág. 41; y MUÑOZ ARANGUREN, "La curiosidad...", op. cit.

(219) AATS de 1 de febrero de 2017 (Rec. Queja 98/2016), de 30 de marzo de 2017 (Rec. Casación 266/2016), de 16 de junio de 2017 (Rec. Queja 348/2017) y de 18 de julio de 2017 (Rec. Queja 383/2017). En cambio, PÉREZ ESTRADA, Miren Josune, "La exclusiva función del actual recurso de casación contencioso-administrativo ante el Tribunal Supremo», en RVAP núm. 107 (1), 2017, págs. 303-328, considera que el nuevo sistema perjudica los derechos subjetivos de los ciudadanos y es accesible a muy pocos.

(220) A esa finalidad de la reforma alude reiteradamente el TS. Por todos, AATS de 26 de abril de 2017 (Rec. Queja 177/2017) y de 31 de mayo de 2017 (Rec. Queja 28/2017). 
LABURPENA: 7/2015 Lege Organikoak administrazioarekiko auzi- eta kasazioerrekurtso berria ezarri zuen. Bada, ezarpen horren lehenengo balantzea jorratzen da lan honetan, indarrean jarri eta urtebetera bitartekoa. Auzitegi Gorenak lehen urtean egindako doktrina aztertzen da, bai kasazio estatal berria interpretatzeko eta ezartzeko gidalerroak finkatzen dituelako, erreformak planteatutako zalantzei eta galderei erantzute aldera, bai errekurtsoa onartzeari buruzkoa, eta, batez ere, jurisprudentzia sortzeko kasazio-interes objektiboari buruzkoa delako, Onarpen Sekzioari dagokionez. Era berean, kasazio-errekurtso autonomikoaren ezarpenean dauden zailtasunak aztertzen dira.

GAKO HITZAK: Kasazio-errekurtsoa. Administrazioarekiko auzien jurisdikzioa. Auzitegi Gorena. Onarpena. Kasazio-interes objektiboa.

RESUMEN: Este trabajo aborda un primer balance de la implantación del nuevo recurso de casación contencioso-administrativo introducido por la Ley Orgánica 7/2015 al año de su entrada en vigor. Se analiza la doctrina del Tribunal Supremo en el primer año, que fija pautas para la interpretación y aplicación de la nueva casación estatal en respuesta a las dudas y cuestiones planteadas por la reforma y gira en torno a la admisión del recurso y primordialmente sobre el interés casacional objetivo para la formación de jurisprudencia, de apreciación discrecional por la Sección de Admisión. Y también se examinan las dificultades existentes en la implantación del recurso de casación autonómico.

PALABRAS CLAVE: Recurso de casación. Jurisdicción contencioso-administrativa. Tribunal Supremo. Admisión. Interés casacional objetivo.

ABSTRACT: This paper deals with an initial assessment of the implementation of the new cassation appeal introduced by Organic Law 7/2015 at the year of entry into force. It analyzes the doctrine of the Supreme Court in the first year, which sets guidelines for the interpretation and application of the new cassation system in response to the doubts and questions raised by the reform and revolves around the admission of the resource and primarily on the cassational objective interest for the formation of case-law, of discretionary appreciation by the Admission Section. And it also examines the difficulties in the implementation of the regional cassation appeal.

KEYWORDS: Cassation appeal. Administrative jurisdiction. Supreme Court. Admission. Cassational objective interest. 